\title{
FINAL TECHNICAL REPORT: AGE STRENGTHENING OF GRAY CAST IRON PHASE III
}

\author{
By \\ Von L. Richards, University of Missouri-Rolla \\ Metallurgical Engineering Dept \\ 1873 Miner Circle \\ Rolla, MO 65409 \\ VONLR@UMR.edu \\ and \\ Wayne Nicola, Consultant \\ 2082 County Farm Road \\ Warsaw, IN 46580 \\ Wnicola@Kconline.com
}

Produced Under Contract Number: DE-FC07-00ID13851 with Tri-State University. University of Missouri Rolla Serving as Subcontractor

Disclaimer: "Any opinions, findings, and conclusions or recommendations expressed in this material are those of the author(s) and do not necessarily reflect the views of the Department of Energy."

Date of Manuscript June 26, 2003

Report Number DOE/ID13851 
Table of Contents

Section

Executive Summary

Page

Accomplishments

Abstract

4

I Introduction

5

II Summary of Activities

6

III Results

IV Discussion of Results

V Conclusions and Recommendations

29

VI List of Papers Produced During this Contract

33

VII Acknowledgements

35

VIII References 


\section{$\underline{\text { Executive Summary }}$}

It has been proven that aging gray cast iron at room temperature can alter strength and hardness. Controlling the aging process would be a great advantage for metal casters; they could optimize the strength or the yield of their castings. This research characterizes that process and contributes to providing a model for the aging of gray and ductile cast irons. The materials used for study were practical gray cast iron and ductile cast iron produced in production foundries. The results include analyzing the evolution of strength and hardness due to aging, and the impact of aging on machinability.

Preliminary work has demonstrated that age strengthening also occurs in as cast ductile (spheroidal graphite) iron.

This research proved the effectiveness of aging the iron at room temperature, since almost $90 \%$ of the irons studied showed aging at room temperature. It was also possible to accelerate the aging by modestly raising the temperature. A clear correlation exists between machinability and aged iron. At the beginning of the program some existing specifications implied a thirty-day aging time. This work showed the most of room temperature aging occurs during six to ten days from casting. Consequently, foundries that have deployed the technology gained an immediate savings in inventory costs. The potential for accelerating the process to just hours with low temperature heat treatment has been demonstrated.

The public benefits of the research is due to cast irons being widely used in industry and are materials encountered in everyone's day-to-day life in applications such as transportation and machine components. Gray iron is the material of choice in applications where wear resistance, machinability or heat transfer is an important selection criterion. It is widely used in automotive and truck brake and power transmission components. Age strengthening permits the use of more easily processed compositions, resulting in less energy used to melt the alloy for a specific application. This composition adjustment has been employed by one of the sponsoring foundries in their brake and clutch product line. Increasingly, ductile iron replaces steel for high strength components. It has become an economical choice for high performance complex ferrous parts. Age strengthening has been demonstrated for two of the common grades of ductile iron (spheroidal graphite iron), but the effects of age strengthening on machinability of this alloy system remains to be determined. More research is needed on ductile iron. 


\section{Accomplishments}

The primary objective of this research is to identify the age strengthening mechanism in gray and ductile cast iron, and to quantify the parameters that control it. It is also to contribute to a new predictive model for gray and ductile iron strength and hardness. This work shows that age strengthening occurs on a sigmoidal-logarithmic scale in gray and ductile cast irons, to a statistically significant extent. This is similar to Avrami-Johnson-Mehl kinetics for phase transformations in metals. It occurs in both cupola-melted iron and induction melted iron. However, it does not happen in all compositions. We have developed some understanding of the process. Data suggests that nitrogen and nitride-forming trace elements have a significant role in the process, but that is yet not fully characterized. Also, the time dependence of the bulk hardness and strength increase, the nano-scale precipitation evidence from neutron scattering, differential scanning calorimetry results and matrix micro-hardness increase in ferrite all indicate that age strengthening occurs by a precipitation or pre-precipitate cluster formation mechanism.

It has been shown that machinability improvements in gray iron occur with similar time dependence as the strength increase and hardness increase. Due to the sigmoidal shape of the curve, most of the improvement has occurred in six to ten days rather than the thirty days previously assumed in some specifications. This has reduced inventory in casting and machining facilities. The increased strength has allowed some foundries to move their compositions to higher carbon equivalent and save melting energy due to good casting yield improvement. 


\begin{abstract}
$\underline{\text { Abstract }}$
The research reported below started with a seed grant from AFS sponsored research, which statistically verified the occurrence of age strengthening of gray cast irons. The work was then funded by USDOE under the CMC program. 87.5\% (28 of 32) of the production irons evaluated have shown age strengthening. Age strengthening up to $13.5 \%$ occurs in iron both produced from both cupola and induction furnace melting. Characteristics of the process suggest a precipitation or pre-precipitate cluster formation in the ferrite phase of the matrix as a mechanism. Accompanying hardness increases, neutron scattering evidence for nano-precipitate formation, micro-hardness increases in the ferrite matrix phase and differential scanning calorimetry work, support this mechanism. The effect of aging on machinability was also analyzed. The kinetics of machinability improvement in gray cast iron corresponds to the strength increase.

This phase of the project included a preliminary study to ductile iron grades, some of which indicated a significant increase in strength.
\end{abstract}

Nitrogen may be a significant contributor to age strengthening either through nitride or carbo-nitride formation. 


\section{Introduction}

This research was initiated based on seed work sponsored by the American Foundry Society (Nicola \& Richards, 1998, 1999) where it was statistically proven that gray cast irons can age strengthen at room temperature as much as $13.5 \%$ after holding up to sixty days after the day of casting. The amount of aging is time dependent and the time dependence is logarithmic, and follows closely the Avrami sigmoidal shape in most cases. Age strengthening occurs in both cupola and induction furnace irons. Twenty one additional irons have been tested. Seventeen gray cast irons from cupola and induction melting, four ductile irons, including a quench and temper grade; and one resolutionized (accelerated aging) gray iron. A total of thirty-two different irons from eleven separate foundries have been tested. Twenty-eight of the irons have shown statistically significant age strengthening. Hardness also increases with aging, particularly in the ferrite phase of the matrix. Kinetic studies have shown that utilizing a relatively low temperature heat treatment cycle can speed up the aging process. Two as-cast experiments and one resolutionizing experiment demonstrated this theory. Resolutionizing experiments have demonstrated that the process can be restarted. An attempt was made to determine and correlate the amount of free nitrogen with age strengthening, but these tests have suggested amounts less than ten parts per million so far.

\section{Summary of Activities}

\section{$\underline{\text { Additional Aging Studies }}$}

Age strengthening studies were expanded from the AFS-sponsored seed research to include five additional foundries in addition to re-testing three of the first four foundries of this research. For gray iron, test bars were produced and machined in conformance to ASTM A48 and SAE J431 specifications using a standard 1.2-in B bar. Test bar cooling time prior to shakeout followed the participating foundries normal procedure, which in most cases was tern to fifteen minutes. The normal shakeout time was designed to duplicate the average temperature of castings at shakeout. In order to get a good estimate of the test bar shakeout temperature, two test bar molds were produced with a thermocouple placed in the area of the test bar gauge length. Two added tests were performed where a set of test bars was allowed to mold cool for 30 minutes prior to shakeout. These late shakeout experiments also showed age strengthening even though the shakeout temperature was about $204^{\circ} \mathrm{C}\left(400^{\circ} \mathrm{F}\right)$. After shakeout, the test bars were allowed to cool in still air to room temperature (approx. $75^{\circ} \mathrm{F}$ ). Ductile iron bars were made according to ASTM A 536-84 with a gauge diameter of 0.375 \pm 0.007 in and a gauge length of 1.4 in. Bars were allowed to cool 45 minutes before shakeout.

Because the age strengthening appears to be influenced by test bar holding temperature, in order to minimize the effect of transportation time, the test bars were 
stored in ice at $0^{\circ} \mathrm{C}\left(32^{\circ} \mathrm{F}\right)$ or dry ice at $-92^{\circ} \mathrm{C}\left(-170^{\circ} \mathrm{F}\right)$ prior to machining and testing of day one castings.

In order to maximize the statistical significance to test results, most data points represent an average of five test bars from the same iron. Also extra effort was used to ensure a smooth surface finish and that bars were kept cool (below $60^{\circ} \mathrm{C}\left(140^{\circ} \mathrm{F}\right)$ ) during machining.

\section{Nitrogen Analysis}

Work from phase II and phase III has indicated that nitrogen is a factor in the age strengthening observed in all of the irons that have been tested. Tests were conducted to determine the consistency of analysis from test bars and how best to prepare samples for analysis using the inert gas fusion method. Experimental work has also carried out in an effort to develop a rapid method of analysis for determining both combined (acid insoluble) and dissolved (acid soluble) nitrogen. Neutron scattering was used to examine the role of precipitates and solid solution in the ferrite phase of the microstructure. Differential scanning calorimetry work was done to get an idea if a precipitation reaction was involved.

\section{$\underline{\text { Artificial Aging Studies }}$}

This research indicated that age strengthening is probably a temperature dependent process. It was reasoned that holding test bars at an elevated temperature could speed up the age strengthening process and that holding at a low temperature would slow the age strengthening. Kinetic studies were conducted, attempting to accelerate the aging process by holding test bars at $70^{\circ} \mathrm{C}\left(185^{\circ} \mathrm{F}\right), 149^{\circ} \mathrm{C}\left(360^{\circ} \mathrm{F}\right)$, and $233^{\circ} \mathrm{C}\left(545^{\circ} \mathrm{F}\right)$ for varying periods of time. The elevated temperature aging was conducted as soon as possible after casting with results being compared to bars from the same iron tested on day one and after 60 days at room temperature. A water bath at $70^{\circ} \mathrm{C}\left(185^{\circ} \mathrm{F}\right)$ was used for the lower temperature work and an electrical resistance furnace was used for holding at $149^{\circ} \mathrm{C}\left(360^{\circ} \mathrm{F}\right)$ and $233^{\circ} \mathrm{C}\left(545^{\circ} \mathrm{F}\right)$. A thermocouple inserted into a test bar was used to monitor the time at temperature.

One resolutionizing experiment was run using fully aged test bars from foundry D. In this resolutionizing experiment, the resolutionizing temperatures were selected to bracket the invariant reaction temperatures in the Fe-N system ( Malinov, et al, 2001) Solution treatment temperatures were chosen to examine four different regions within the Fe-N phase diagram (see figure 1). The experimental temperatures were $850 \mathrm{~K}, 890 \mathrm{~K}$, $940 \mathrm{~K}$, and $977 \mathrm{~K}$. The effectiveness of these temperatures gives some insight into the nitride present in the gray iron during solution treatment. For instance, $977 \mathrm{~K}$ was chosen because $\mathrm{Fe}_{4} \mathrm{~N}$ will completely dissolve at this temperature and a preliminary study had shown strength loss and partial regain of strength on aging after using this as a resolutionizing temperature. Using $772 \mathrm{~K}$ in the same preliminary study had no effect of lowering strength 
The samples used were tensile bars remaining from previous test work. The bars were heated to the desired temperature in a muffle furnace. A center-drilled dummy bar was used to monitor the temperature within the test bars. The bars were removed from the furnace 1-2 seconds after achieving the desired temperature and quenched in room temperature water. This quench was followed by a quench in ice water and then a quench in liquid nitrogen. The heat-treated samples were stored in liquid nitrogen until tensile testing could be performed to prevent aging of the gray iron. The samples were brought up to room temperature using room temperature water and then pulled in a tensile tester. Bars from the same lot of material were pulled without heat treatment to produce a tensile strength prior to heat treatment. The change in tensile strength was then compared to determine the effectiveness of the solution heat treatment. The remaining bars were aged at room temperature 30 days. Precision Brinell measurements were also made concurrently.

A resolutionizing experiment with elevated temperature aging was run in attempt to monitor and understand better the kinetics of age strengthening. Bars were copper plated. They were divided into five groups. A first heat treatment was performed on each group using an electric oven for 10 minutes at $600{ }^{\circ} \mathrm{C}$. Then, a second heat treatment was done using a convection oven. The times were 1 minute, 20 minutes, 1 hour, 3 hours, and 9 hours. The temperature was $83{ }^{\circ} \mathrm{C}$. Those times were found from a previous resolutionizing experiment. The temperature for the second heat treatment was found from the diffusivity data of nitrogen in iron.

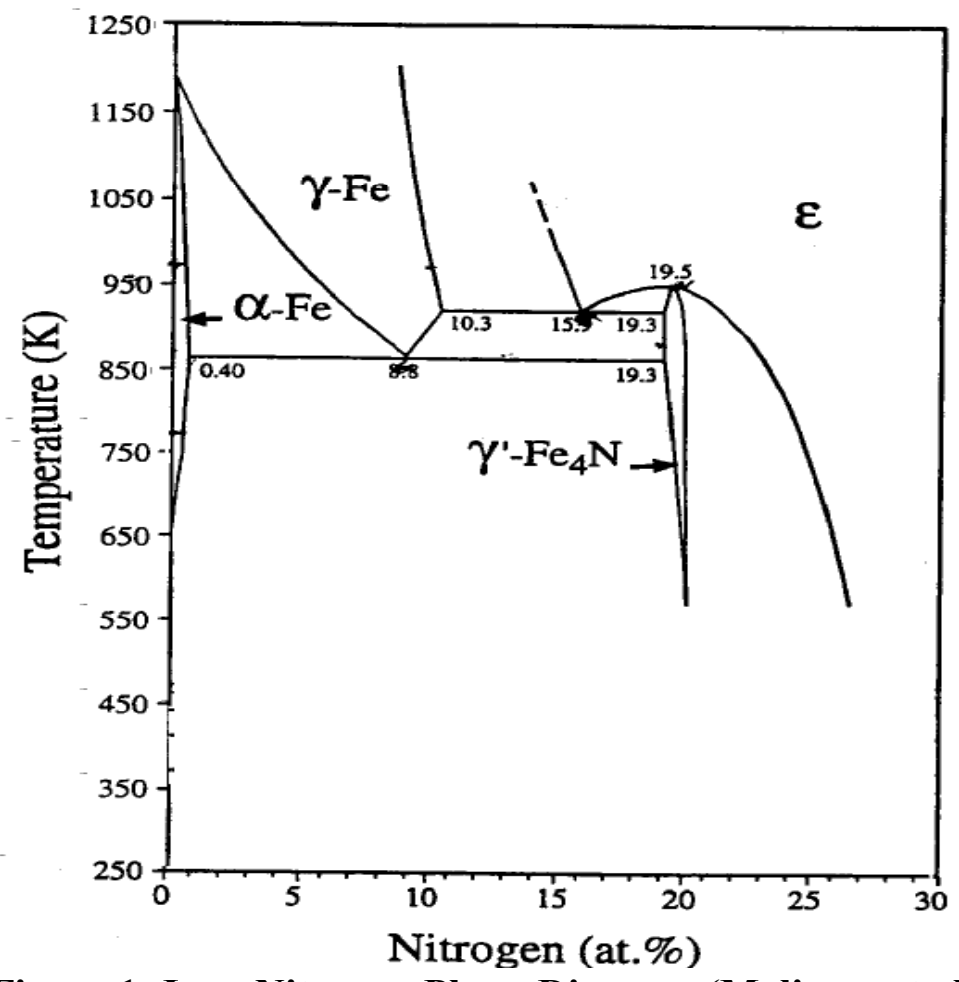

Figure 1: Iron-Nitrogen Phase Diagram (Malinov, et al, 2001) Machinability Study 
In-plant machinability tests were conducted at participants or their machining customers with accompanying age strengthening studies. The machinability studies were done using manufacturing measures of machinability such as tool replacement frequency, deterioration of product measurable parameters such as surface finish or parallelism between sides of clutch plates or brake disks ("tilt"). These are used in manufacturing as criteria for tool adjustment or replacement rather than a measured wear land.

\section{$\underline{\text { Ductile Iron }}$}

A preliminary study of age strengthening in ductile cast iron has also been included in the extended scope of the project. Four different irons including a quench and tempered grade were considered. The quench and temper process was accomplished at a commercial heat treater. Unfortunately, one of them was inconclusive due to sulfur contamination in the ladle. Tensile testing, Brinell hardness measurements, Vickers microhardness measurements, and nitrogen analysis were performed.

\section{$\underline{\text { Microhardness }}$}

Microhardness measurements in the free ferrite regions were taken for one of the ductile iron tests. To study the strengthening effects of aging, a microhardness technique was used instead of the conventional Brinell hardness testing method. Microhardness testing allows us to specifically measure the hardness of the matrix alone, while in the Brinell hardness testing the hardness values obtained give the hardness of the matrix as well as the graphite nodules. Though, Brinell measurements were still made for that particular ductile iron. The microhardness tests were conducted with Vickers diamond pyramid indenter under test load of $10 \mathrm{gf}$ at room temperature. The load was applied for $15 \mathrm{~s}$. In order to have results with statistical significance, 25 indentations were performed for each bar throughout the surface giving a total of 50 measurements on samples aged for a particular period of time.

\section{Results}

\section{$\underline{\text { Additional Aging Studies }}$}

A total of ten different foundries have been evaluated to determine if age strengthening occurs and if so, the magnitude of the increase in strength. Thirty-two separate studies have been conducted at these foundries with statistically significant room temperature age strengthening occurring in 28 of the 32 irons evaluated. The increase in strength ranged from $3.8 \%$ to a high of $13.5 \%$. Table I is a summary of these tests. A small study was conducted to accurately determine the temperature of the test bars at different shakeout times. Two separate tests were made using a thermocouple in the test bar gage diameter to obtain a temperature profile during cooling. Figure 2 is a copy of 
this cooling curve. With a ten-minute shakeout time, the temperature of the bar is approximately $622^{\circ} \mathrm{C}\left(1400^{\circ} \mathrm{F}\right)$, with a fifteen minute shakeout, the temperature of the bare is $718^{\circ} \mathrm{C}\left(1325^{\circ} \mathrm{F}\right)$ and with a thirty minute shakeout time, the temperature is approximately $451^{\circ} \mathrm{C}\left(1025^{\circ} \mathrm{F}\right)$. The objective was to evaluate shakeout temperatures above and below the eutectoid transformation temperature. With shakeout times, up to thirty minutes, there does not appear to be any effect on age strengthening. It is apparent from data sets D- $4 \& 5$ and G- $2 \& 3$ that the longer shakeout time lowered the test bar strength but it does not effect the occurrence of age strengthening of the iron. Test bars shaken out at $451^{\circ} \mathrm{C}\left(1025^{\circ} \mathrm{F}\right)$ exhibited the same percentage of age strengthening as bars shaken out at $622^{\circ} \mathrm{C}\left(1400^{\circ} \mathrm{F}\right)$. 
Table 1 - Data Summary for Aging Studies.

\begin{tabular}{|c|c|c|c|c|c|c|c|c|c|c|}
\hline Foundry & $\begin{array}{l}\text { Aging } \\
\text { Time }\end{array}$ & $\begin{array}{c}\text { BASE } \\
\text { STRENGTH }\end{array}$ & $\begin{array}{c}\text { AGED } \\
\text { STRENGTH }\end{array}$ & $\begin{array}{c}\% \\
\text { INCREASE }\end{array}$ & C E & Carbon & Silicon & Titanium & Nitrogen & Comments \\
\hline Test & & PSI & PSI & & & & & & & \\
\hline A-1 & 60 days & 35050 & 38500 & $9.80 \%$ & $4.16 \%$ & $3.40 \%$ & $2.29 \%$ & $0.03 \%$ & $0.01 \%$ & \\
\hline A-2 & 60 days & 38000 & 39750 & $4.60 \%$ & $4.09 \%$ & $3.33 \%$ & $2.31 \%$ & $0.03 \%$ & $0.01 \%$ & \\
\hline A-3 & 60 days & 33410 & 37550 & $12.40 \%$ & $4.13 \%$ & $3.40 \%$ & $2.18 \%$ & $0.03 \%$ & $0.01 \%$ & \\
\hline A-4 & 60 days & 34100 & 37150 & $8.90 \%$ & $4.15 \%$ & $3.42 \%$ & $2.20 \%$ & $0.04 \%$ & $0.01 \%$ & \\
\hline A-5 & 60 days & 36050 & 39550 & $9.70 \%$ & $4.09 \%$ & $3.38 \%$ & $2.14 \%$ & $0.03 \%$ & $0.01 \%$ & \\
\hline B-1 & 60 days & 36700 & 36200 & $-1.40 \%$ & $4.16 \%$ & $3.47 \%$ & $2.07 \%$ & $0.03 \%$ & $0.01 \%$ & \\
\hline B-2 & 60 days & 36550 & 36550 & $0.00 \%$ & $4.17 \%$ & $3.48 \%$ & $2.07 \%$ & $0.03 \%$ & $0.01 \%$ & \\
\hline B-3 & 60 days & 35650 & 37000 & $3.80 \%$ & $4.14 \%$ & $3.41 \%$ & $2.18 \%$ & $0.03 \%$ & $0.01 \%$ & \\
\hline $\mathrm{C}-1$ & 60 days & 39700 & 43900 & $10.60 \%$ & $4.22 \%$ & $3.49 \%$ & $2.19 \%$ & $0.02 \%$ & $0.01 \%$ & \\
\hline $\mathrm{C}-2$ & 60 days & 39650 & 45000 & $13.50 \%$ & $4.19 \%$ & $3.47 \%$ & $2.17 \%$ & $0.02 \%$ & $0.01 \%$ & \\
\hline D-1 & 60 days & 40550 & 44150 & $8.90 \%$ & $4.19 \%$ & $3.49 \%$ & $2.11 \%$ & $0.02 \%$ & $0.01 \%$ & \\
\hline D-2 & 60 days & 33400 & 36250 & $8.50 \%$ & $4.19 \%$ & $3.47 \%$ & $2.17 \%$ & $0.05 \%$ & $0.01 \%$ & \\
\hline D-3 & 60 days & 40650 & 44350 & $9.10 \%$ & $4.16 \%$ & $3.47 \%$ & $2.08 \%$ & $0.02 \%$ & $0.01 \%$ & \\
\hline D-4 & 60 days & 42450 & 44600 & $5.10 \%$ & $4.17 \%$ & $3.46 \%$ & $2.12 \%$ & $0.01 \%$ & $0.01 \%$ & \\
\hline D-5 & 60 days & 37600 & 40250 & $7.00 \%$ & $4.17 \%$ & $3.46 \%$ & $2.12 \%$ & $0.01 \%$ & $0.01 \%$ & 30 min shakeout \\
\hline D-6 & 60 days & 42450 & 43800 & $3.30 \%$ & $4.17 \%$ & $3.46 \%$ & $2.12 \%$ & $0.01 \%$ & $0.01 \%$ & stored in freezer \\
\hline D-7 & 60 days & 42450 & 44350 & $4.60 \%$ & $4.17 \%$ & $3.46 \%$ & $2.12 \%$ & $0.01 \%$ & $0.01 \%$ & $\begin{array}{l}\text { Resolutionized@930 } \\
{ }^{\circ} \mathrm{F}\end{array}$ \\
\hline D-8 & 60 days & 36300 & 39200 & $8.00 \%$ & $4.23 \%$ & $3.52 \%$ & $2.14 \%$ & $0.01 \%$ & $0.01 \%$ & \\
\hline D-9 & 60 days & 36300 & 34850 & $-4.00 \%$ & $4.23 \%$ & $3.52 \%$ & $2.14 \%$ & $0.01 \%$ & $0.01 \%$ & $\begin{array}{l}\text { Resolutionized@1300 } \\
{ }^{\circ} \mathrm{F}\end{array}$ \\
\hline \multirow[t]{2}{*}{$\begin{array}{l}D-10 \\
D-11\end{array}$} & 20 days & 37150 & 39450 & $6.25 \%$ & $4.19 \%$ & $3.47 \%$ & $2.19 \%$ & $0.008 \%$ & 0.0076 & \multirow[t]{2}{*}{$\begin{array}{c}\text { Gray Iron } \\
\text { Resolutionized @ 83C }\end{array}$} \\
\hline & 9 hours & 38850 & 39600 & $1.93 \%$ & N/A & N/A & N/A & N/A & N/A & \\
\hline $\mathrm{X}$ & 60 days & 47700 & 50550 & $6.00 \%$ & $4.04 \%$ & $3.51 \%$ & $1.59 \%$ & $0.01 \%$ & $0.01 \%$ & \\
\hline E-1 & 60 days & 33000 & 35450 & $7.40 \%$ & $4.22 \%$ & $3.48 \%$ & $2.21 \%$ & $0.02 \%$ & $0.01 \%$ & \\
\hline E-2 & 60 days & 28250 & 30200 & $6.90 \%$ & $4.17 \%$ & $3.41 \%$ & $2.29 \%$ & $0.04 \%$ & $0.01 \%$ & \\
\hline E-3 & 60 days & 43350 & 45150 & $4.20 \%$ & $4.11 \%$ & $3.43 \%$ & $2.05 \%$ & $0.02 \%$ & $0.01 \%$ & \\
\hline F-1 & 60 days & 27400 & 29000 & $5.90 \%$ & $4.28 \%$ & $3.54 \%$ & $2.22 \%$ & $0.01 \%$ & $0.00 \%$ & \\
\hline $\mathrm{F}-2$ & 30 days & 74400 & 77900 & $4.70 \%$ & $4.62 \%$ & $3.75 \%$ & $2.64 \%$ & $0.006 \%$ & $0.0072 \%$ & Ductile Iron \\
\hline F-3 & 30 days & 111100 & 112100 & $0.90 \%$ & $4.43 \%$ & $3.62 \%$ & $2.45 \%$ & $0.006 \%$ & $0.0082 \%$ & Ductile Iron \\
\hline $\begin{array}{l}\text { F-4 } \\
\text { F-5 }\end{array}$ & 29 days & 30300 & 32500 & $7.26 \%$ & $4.27 \%$ & $3.56 \%$ & $2.16 \%$ & $0.010 \%$ & $0.0053 \%$ & \\
\hline F-5 & 29 days & 35550 & 38000 & $6.90 \%$ & 4.22 & $3.53 \%$ & $2.10 \%$ & $0.010 \%$ & $0.0082 \%$ & $\begin{array}{l}\text { Same as F-4, but with } \\
\text { N-FeMn }\end{array}$ \\
\hline G-1 & 60 days & 39600 & 43550 & $10.00 \%$ & $4.02 \%$ & $3.27 \%$ & $2.24 \%$ & $0.01 \%$ & $0.01 \%$ & \multirow[b]{3}{*}{30 min Shakeout } \\
\hline G-2 & 60 days & 47800 & 52900 & $10.70 \%$ & $4.09 \%$ & $3.34 \%$ & $2.25 \%$ & $0.01 \%$ & $0.01 \%$ & \\
\hline G-3 & 60 days & 43700 & 48300 & $10.50 \%$ & $4.09 \%$ & $3.34 \%$ & $2.25 \%$ & $0.01 \%$ & $0.01 \%$ & \\
\hline $\mathrm{H}-1$ & 60 days & 36150 & 39850 & $10.20 \%$ & $4.21 \%$ & $3.55 \%$ & $1.97 \%$ & $0.02 \%$ & $0.01 \%$ & \\
\hline $\mathrm{K} 1$ & 24 days & 34800 & 37700 & $8.33 \%$ & 4.04 & $3.31 \%$ & $2.20 \%$ & $0.017 \%$ & 0.00347 & \multirow{2}{*}{$\begin{array}{l}\text { Gray Iron, Low N } \\
\text { Same as K-1, but high } \\
\text { N }\end{array}$} \\
\hline $\mathrm{K} 2$ & 24 days & 36250 & 40150 & $10.76 \%$ & 4.04 & $3.31 \%$ & $2.21 \%$ & $0.017 \%$ & 0.00719 & \\
\hline
\end{tabular}




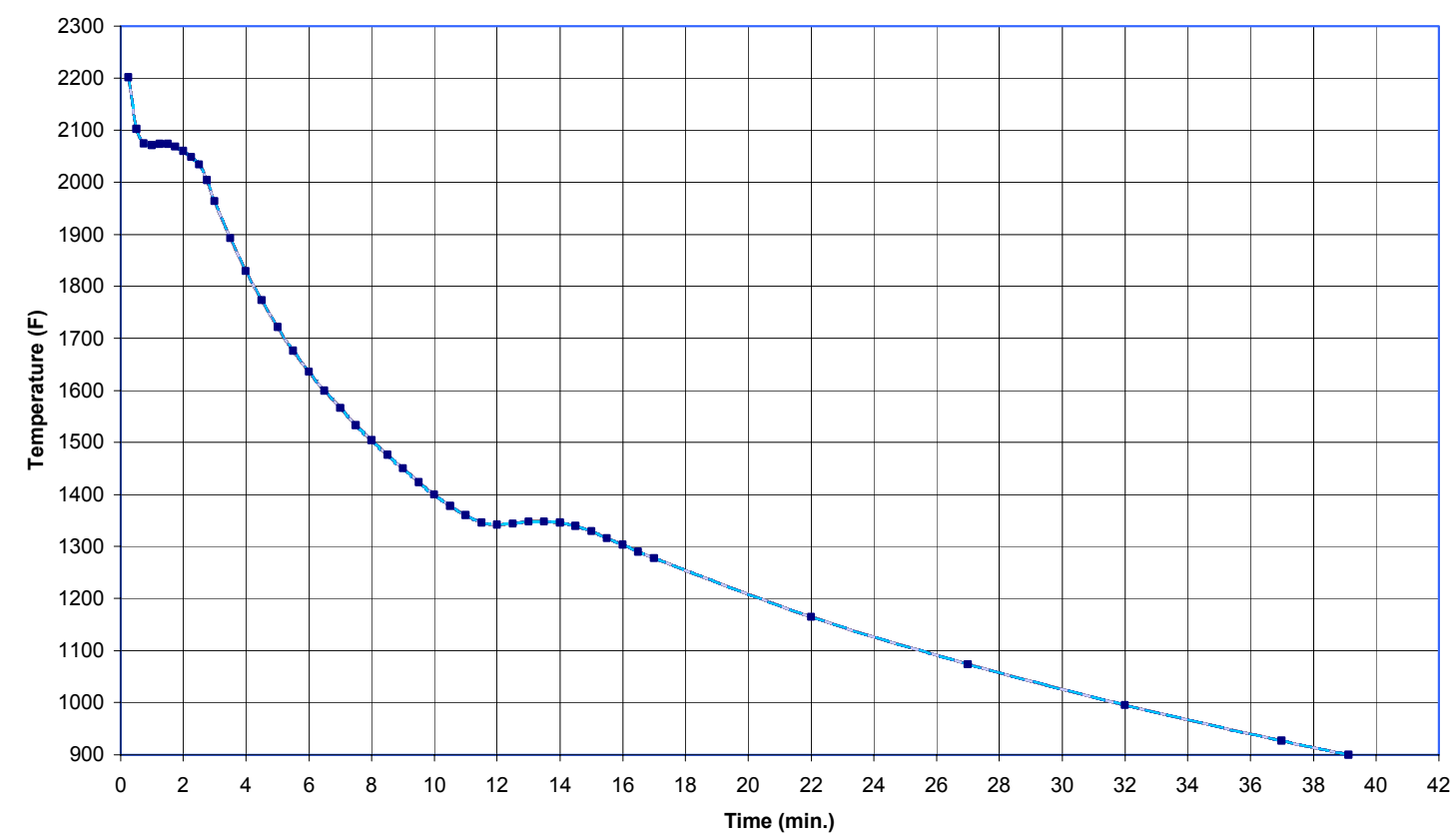

Figure 2 - The test bar cooling curve shows that shakeout at 10 minutes occurs at $760^{\circ} \mathrm{C}$ $\left(1400^{\circ} \mathrm{F}\right)$, at 15 minutes occurs at $718^{\circ} \mathrm{C}\left(1325^{\circ} \mathrm{F}\right)$ and at 30 minutes occurs at about $551^{\circ} \mathrm{C}$ $\left(1025^{\circ} \mathrm{F}\right)$.

\section{Nitrogen Analysis}

Neutron scattering tests were conducted for three gray iron samples at Argonne National Laboratory. These samples were then retested 28 days later to observe any changes in the scattering data. Figures $3 a, 3 b$, and $3 c$ show the scattering data plotted as intensity $(\mathrm{I}(\mathrm{Q}))$ versus scattering vector $(\mathrm{Q})$ for each neutron scattering test for samples 7A, 14A, and 21A, respectively. Sample 7A is a standard gray iron. Sample 14A is a gray iron alloyed with nitrided ferromanganese to increase the nitrogen content. Sample $21 \mathrm{~A}$ is a gray iron alloyed with ferrotitanium to reduce the nitrogen content to very low levels. Specimen thickness varied from $0.15 \mathrm{~mm}$ to $1.37 \mathrm{~mm}$. Figure $2 \mathrm{~b}$ shows a resolved peak at $\mathrm{Q} \sim 0.17 \AA^{-1}$ for sample $14 \mathrm{~A}$ at 28 days (rSN12246). This corresponds to a spherical particle with a diameter of 2-4 $\mathrm{nm}$ or an ordered array of particles with an interparticle spacing of $37 \AA$ (Thiyagarajan, 2001). Figure $3 a$ also seems to show a similar peak, however the scatter in the data does not allow this to be stated with certainty. It should be noted that the resolved peak occurs in the thinnest specimen $(0.31$ $\mathrm{mm}$ ) for sample 14A. Figure $3 \mathrm{c}$ shows that the titanium-rich gray iron did not show any resolved peaks. 

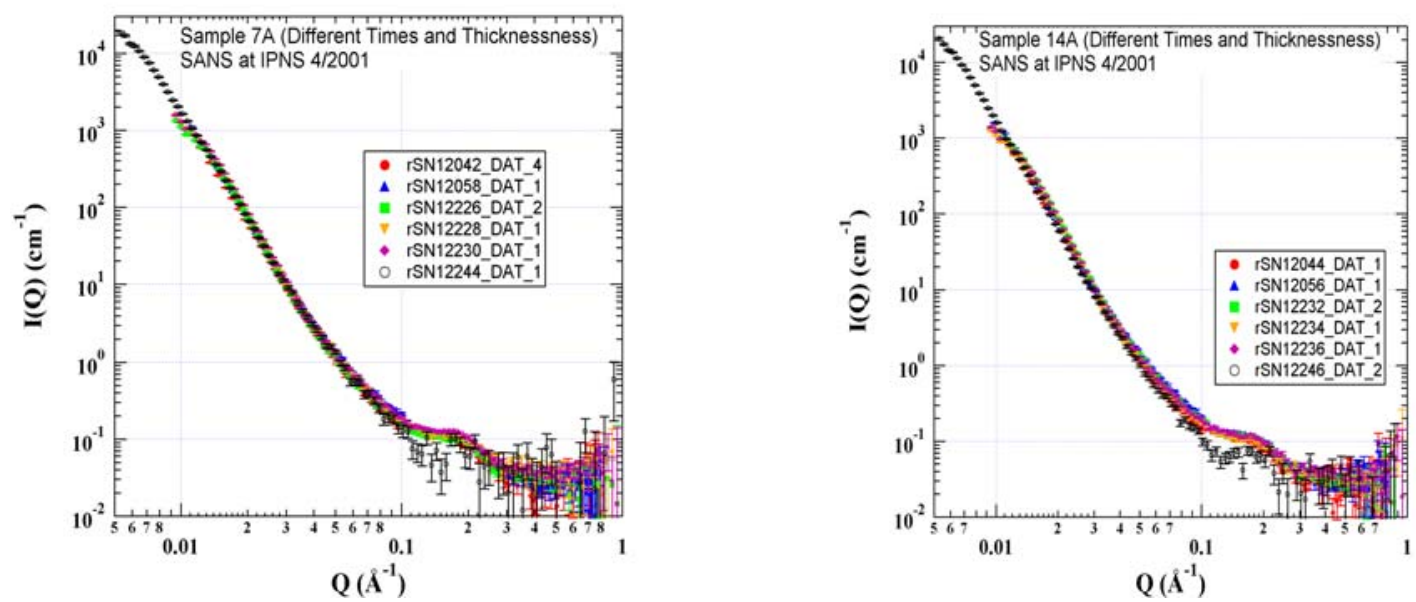

Figure 3a (left): Neutron Scattering Data for Standard Gray Iron Sample 7A. Figure 3b (right): Neutron Scattering Data for Nitrogen-Rich Gray Iron sample 14A.

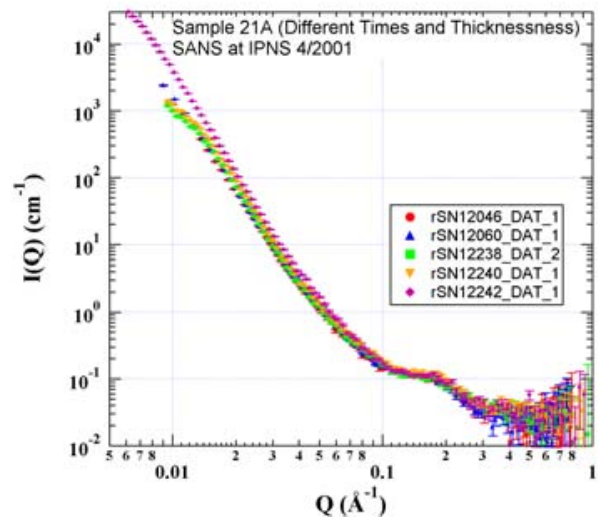

Figure 3c: Data for Titanium Treated Gray Iron Sample 21A.

The effect of free nitrogen on the rate of strengthening was determined by plotting the change in tensile strength with respect to the change in log time (shown as dUTS/dlnt on the vertical axis of figure 4) against the estimated amount of free nitrogen in the gray iron. The free nitrogen was estimated by subtracting away one-third of the weight percent titanium from the total nitrogen in the gray iron. Titanium forms a stable nitride (TiN) and is thus a very strong nitrogen getter. Titanium is three times as heavy as nitrogen, thus one-third of the weight percent titanium should equal the weight percent nitrogen in titanium nitride, assuming all of the titanium is in the form of TiN. In gray cast iron, the titanium reacts with nitrogen to form a complex carbo-nitride, and the effects of other nitride formers are neglected, so this stoichiometric assumption may be flawed. Figure 4 shows that the strengthening rate increases with estimated free nitrogen for foundry $\mathrm{C}$ and $\mathrm{D}$ gray iron. 


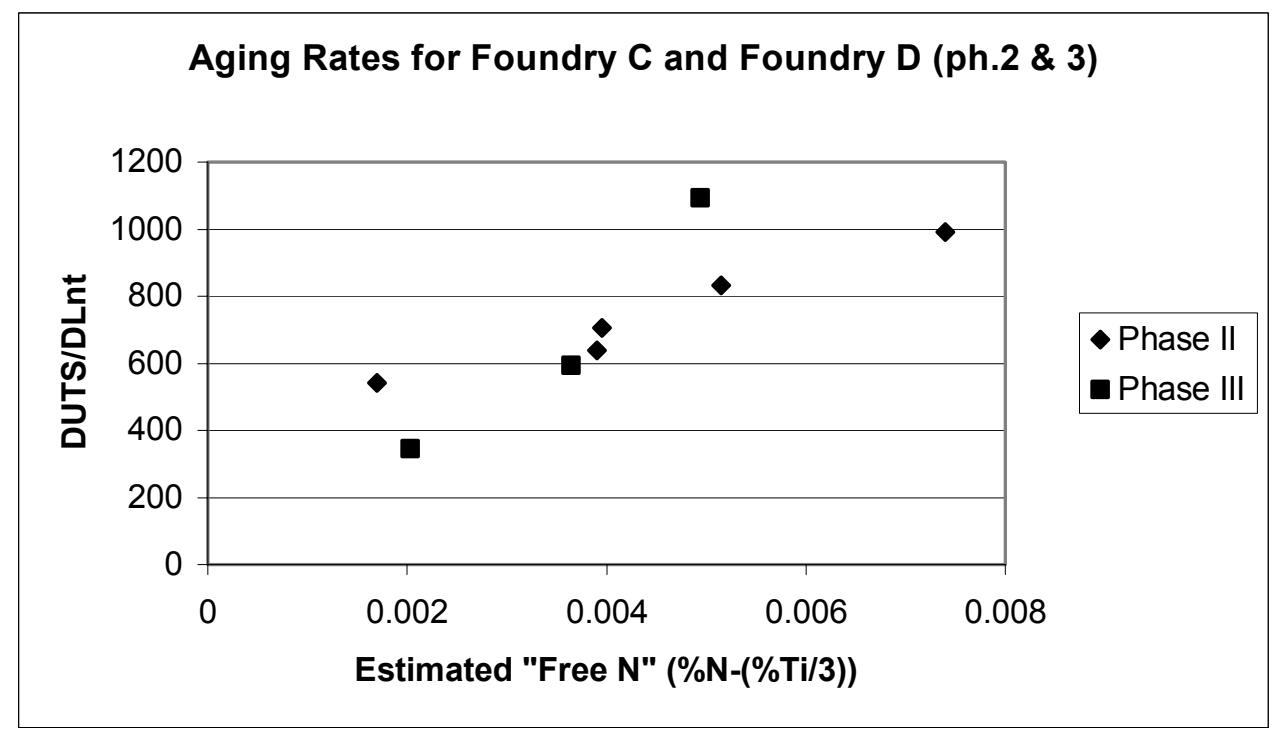

Figure 4: The Effect of Free Nitrogen on the Rate of Age Strengthening for Foundry C and D Gray Iron.

The analysis of the differential scanning calorimetry work for foundry D suggests a transformation from a metastable to a stable precipitate at $250^{\circ} \mathrm{C}$ and the reversal of the eutectoid reaction in the iron nitrogen system at about $630^{\circ} \mathrm{C}$. Running a high nitrogen specimen in the reference cell and a non-aging specimen in the sample cell generates a difference curve (figure 5).

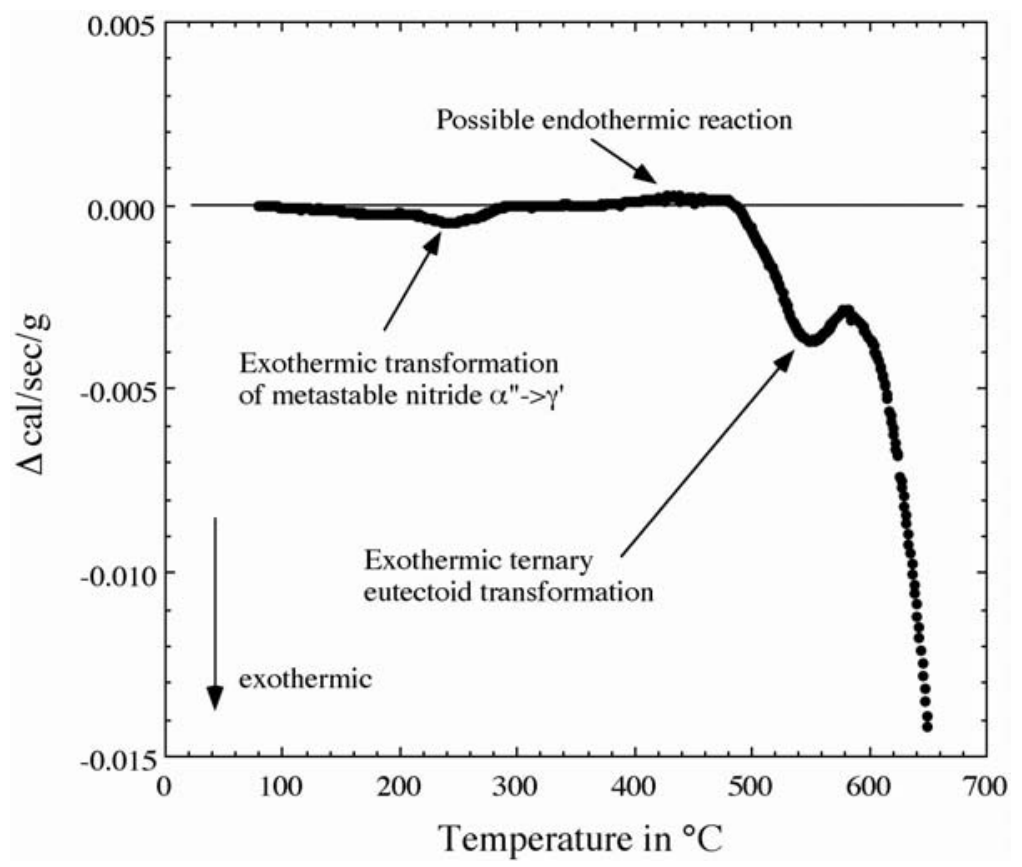

Figure 5: DSC Results. 
Data suggests that nitrogen (figures 4, 6 and 7, and table 2) and nitride-forming trace elements have a significant role in the process, but that is as yet not fully characterized. Total nitrogen content has been measured by inert gas fusion technique, which is included in table 2 .

In trying to determine the free nitrogen in the samples, we began by annealing the samples in a tube furnace at $600^{\circ} \mathrm{C}$ for six hours. When these samples were then tested using a LECO nitrogen analyzer, there was too much scatter in the results. Because of this, it was determined that the samples should be annealed longer. The next set of samples was divided into two groups. The groups would be identical and would still be annealed at $600^{\circ} \mathrm{C}$, but that one group would be annealed for 12 hours and the other group would be annealed for 18 hours. This would help determine at which time we would get the least amount of scatter. The results for both sets of samples were very close, but the 12 hour samples still had some scatter in them while the 18 hour samples were much more reliable. It was determined by looking at the results that the free nitrogen was running between 4 and 6 parts per million. The chemistry and nitrogen contents are displayed in table 2.

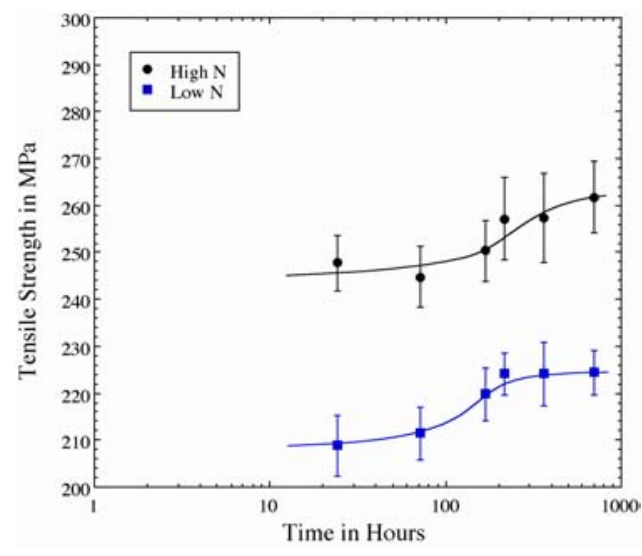

Figure 6: Effects $\mathrm{N}$ on the Tensile Strength of Gray Iron for Foundry F.

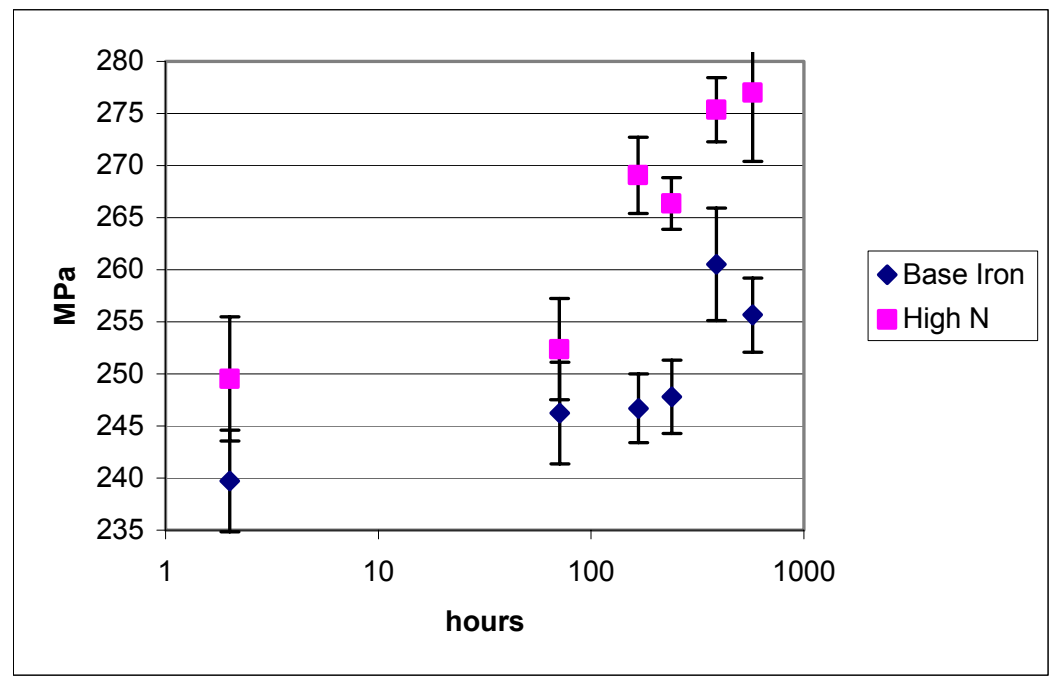

Figure 7: Effects of Nitrogen on the tensile Strength of Gray Iron for Foundry $\mathrm{K}$ 
Table 2: Arc Spectrometer Chemistry and Nitrogen Contents.

\begin{tabular}{|c|c|c|c|c|c|c|c|c|c|c|c|c|c|c|c|c|}
\hline Heat No. & C & $\mathrm{Si}$ & $\mathrm{Mn}$ & $\mathrm{Cr}$ & $\mathrm{P}$ & $\mathrm{S}$ & $\mathrm{Ni}$ & $\mathrm{Cu}$ & $\mathrm{Al}$ & Sn & Mo & $\mathrm{Ti}$ & As & $\mathrm{Sb}$ & B & $\mathrm{N}$ \\
\hline A3 & $10 \%$ & & & & & & & & & & $0.027 \%$ & $0.034 \%$ & & & & \\
\hline A5 & $3.38 \%$ & $2.14 \%$ & $0.61 \%$ & $0.095 \%$ & & $0.105 \%$ & $0.026 \%$ & & $0.004 \%$ & $0.012 \%$ & $0.027 \%$ & $0.030 \%$ & & & $0.0016^{\circ}$ & $100 \%$ \\
\hline B-1 & $3.47 \%$ & $2.07 \%$ & 0.5 & 0.11 & & & & & & & $0.019 \%$ & $0.028 \%$ & & & & \\
\hline B-2 & $3.48 \%$ & & & & & & & & & $6 \%$ & $0.019 \%$ & $0.029 \%$ & & & & $0.0068 \%$ \\
\hline B-3 & $1 \%$ & & & & & & & & & & $0.015 \%$ & $0.026 \%$ & & & & \\
\hline C-2 & $3.49 \%$ & $2.20 \%$ & $0.49 \%$ & $0.142 \%$ & & 0.09 & $0.042 \%$ & 0.18 & 0.00 & 0.01 & $0.041 \%$ & $0.015 \%$ & & & $0.0009 \%$ & $0.0082 \%$ \\
\hline $\mathrm{D} 1$ & $9 \%$ & & & & & & & & & & & & & & & \\
\hline $\mathrm{D}$ & $17 \%$ & 2.1 & & & & & & & & & & & & & & \\
\hline & $7 \%$ & 2.0 & & & & & & & & & & & & & & \\
\hline, 7 & & & & & & & & & & & & & & & & \\
\hline & $56 \%$ & $2.14 \%$ & & & & & & & & & $0.004 \%$ & 0.0 & & & & \\
\hline $\mathrm{F}-2$ & & & & & & & & & & & & & & $0.0013 \%$ & 60. & \\
\hline F-3 & & $2.45 \%$ & & & & & & & & & $0.004 \%$ & 0.0 & & & & \\
\hline F-4 & $3.56 \%$ & $2.16 \%$ & 0.74 & & & $0.079 \%$ & & & & & $0.036 \%$ & $0.010 \%$ & & & $00.0 c$ & 0.0 \\
\hline $\mathrm{F}-5$ & $3.53 \%$ & $2.10 \%$ & $0.82 \%$ & $0.078 \%$ & 0. & $0.100 \%$ & 0.0 & 0.43 & $0.006 \%$ & 0.0 & $0.036 \%$ & $10 \%$ & 0.0 & 0.0 & & $82 \%$ \\
\hline $\mathrm{G}-1$ & $27 \%$ & $2.24 \%$ & & & & & & & & & & & & & & \\
\hline$G-2,3$ & $3.34 \%$ & $2.25 \%$ & $0.99 \%$ & $0.065 \% 0$ & $0.024 \%$ & $0.044 \%$ & $0.000 \%$ & $0.586 \%$ & $0.005 \%$ & $7 \%$ & $0.013 \%$ & $0.011 \%$ & $0.0069 \%$ & $0.0459 \%$ & $0.0011 \%$ & $0.0062 \%$ \\
\hline $\mathrm{H}-1$ & $3.55 \%$ & $1.97 \%$ & $0.54 \%$ & $0.09 \%$ & $0.10 \%$ & $0.140 \%$ & $0.027 \%$ & $0.339 \%$ & $0.004 \%$ & 0.0 & $0.019 \%$ & $0.017 \%$ & $6 \%$ & 0.02 & 0.00 & $0.0074 \%$ \\
\hline & $3.31 \%$ & $2.20 \%$ & $0.59 \%$ & $0.052 \% 0$ & & $0.10 \%$ & $0.000 \%$ & & & & & & & $0.012 \%$ & $0.0014 \%$ & 0.00347 \\
\hline $\mathrm{K}-2$ & $3.31 \%$ & $2.21 \%$ & $0.78 \%$ & $0.053 \% 0$ & $0.063 \%$ & $0.10 \%$ & $0.000 \%$ & $0.253 \%$ & $0.005 \%$ & $0.009 \%$ & $0.106 \%$ & $0.017 \%$ & $0.006 \%$ & $0.011 \%$ & $0.0014 \%$ & 0.00719 \\
\hline & $1 \%$ & $.59 \%$ & $0.65 \%$ & $0.150 \% 0$ & $0.089 \%$ & $0.094 \%$ & $0.110 \%$ & $50 \%$ & & $0.015 \%$ & $.050 \%$ & $14 \%$ & & & & \\
\hline
\end{tabular}




\section{$\underline{\text { Artificial Aging and Solution Treatment Studies }}$}

The first artificial aging study used freezer storage at $-13^{\circ} \mathrm{C}\left(4^{\circ} \mathrm{F}\right)$ to inhibit aging during machining and prior to elevated temperature treatment. Subsequently, we found that over a sixty-day time, the freezer storage did inhibit aging but only partially. The first kinetic aging study is shown in figure 8 . The strength increased faster with an aging temperature of $149^{\circ} \mathrm{C}\left(360^{\circ} \mathrm{F}\right)$ versus $70^{\circ} \mathrm{C}\left(185^{\circ} \mathrm{F}\right)$. Since the artificial aging samples were kept in a freezer and the room temperature samples were not, we are not certain of the "real" start time of aging in this study. The strength of this heat of iron was 308 MPA (44600 PSI) after sixty days of aging. Therefore we did not age to maximum strength, and based on the slopes of the curves, it is suggested, but not conclusively shown that the artificially aged samples were not over aged.

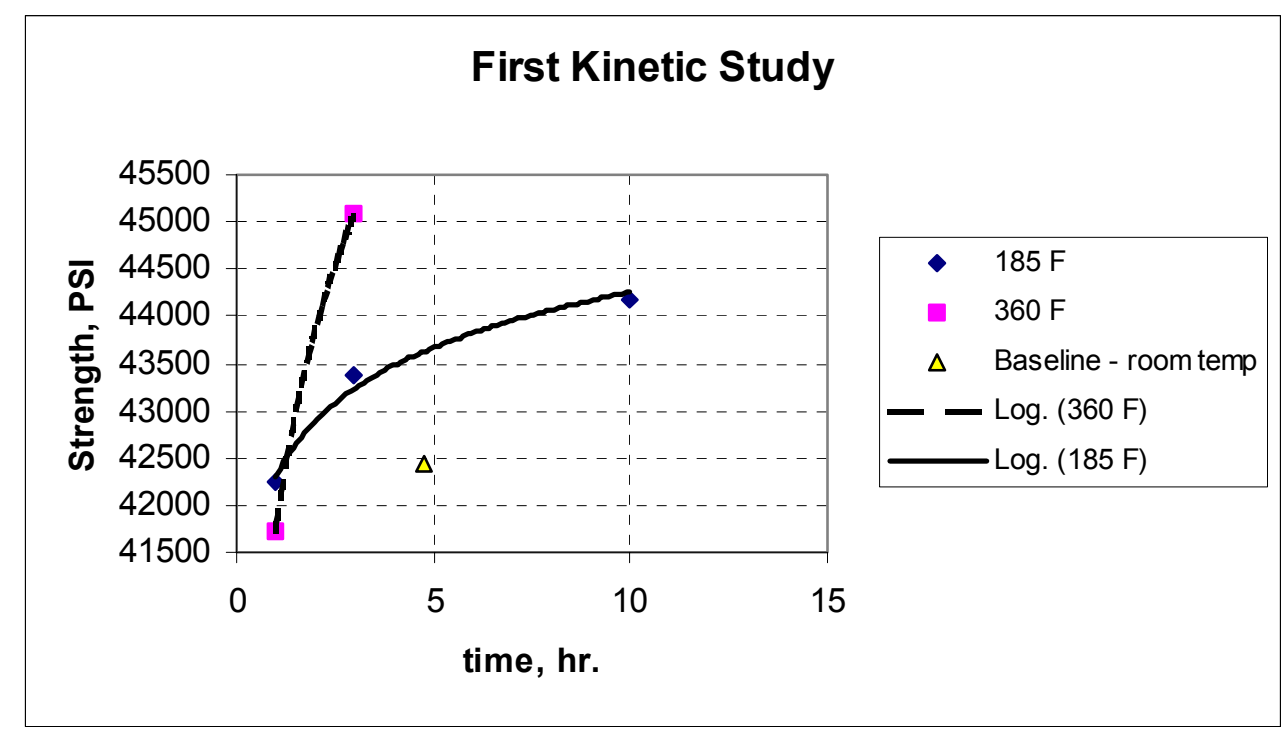

Figure 8 -- First accelerated aging study shows that strengthening occurs more rapidly at $149^{\circ} \mathrm{C}\left(360^{\circ} \mathrm{F}\right)$ than at $70^{\circ} \mathrm{C}\left(185^{\circ} \mathrm{F}\right)$.

In the second artificial aging study, dry ice was used to keep the samples cold (delay the aging process). The samples were water cooled after shakeout and air-cooling, then stored in dry ice until and between machining operations. They were kept on dry ice until artificial aging heat treatment. The temperature was measured during the aging process using a dummy test bar with a hole drilled into the center axially, ending at the center of the gage length. In that way the aging time was counted from the time the bar reached the target temperature $\left( \pm 3^{\circ} \mathrm{C}\right)$. The time at $149^{\circ} \mathrm{C}\left(360^{\circ} \mathrm{F}\right)$ was extended to ten hours and an additional higher temperature of $233^{\circ} \mathrm{C}\left(545^{\circ} \mathrm{F}\right)$ was also evaluated. The maximum strength after room temperature aging for sixty days was 270 MPA (39180 PSI). This would indicate that we are near the maximum strength at $149^{\circ} \mathrm{C}\left(360^{\circ} \mathrm{F}\right)$ for ten hours and that at $233^{\circ} \mathrm{C}\left(545^{\circ} \mathrm{F}\right)$, we are either near the maximum at three hours or the maximum strength occurred between one and three hours. The data is shown in figure 9 . We note that the maximum strength at sixty days was lower than the sixty-day strength 
for the iron used in the first study, because this was a higher carbon equivalent iron. The participating foundry had taken advantage of the age strengthening effect to alter composition for improved casting yield and consequent energy savings.

Attempts to resolutionize the iron from the first kinetic study at $408^{\circ} \mathrm{C}\left(930^{\circ} \mathrm{F}\right)$ ten seconds resulted in no significant strength reduction. However treatment at $704^{\circ} \mathrm{C}$ $\left(1300^{\circ} \mathrm{F}\right)$ for ten seconds did indicate a strength loss that was recovered after aging. This tends to guide the investigators away from nitrogen-dislocation-core interaction as a strengthening mechanism. Nitrogen still may play a role, but there may be a nitride or carbo-nitride of iron or boron of importance.

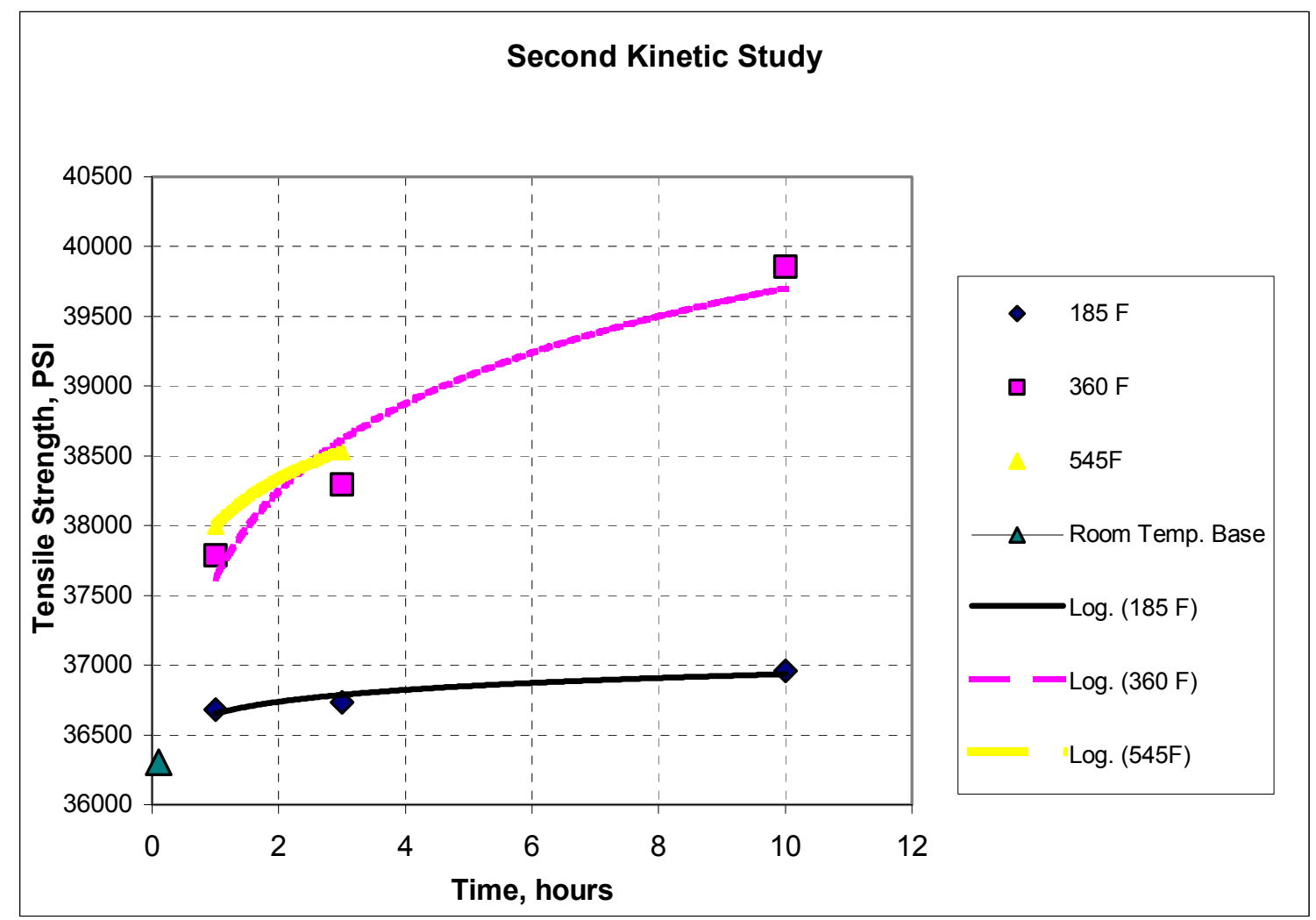

Figure 9: The Second Accelerated Aging Study Showed Similar Results on a Higher CarbonEquivalent Alloy with Better Temperature Control During Aging.

Another resolutionizing experiment was made on a gray iron grade from foundry $\mathrm{D}$, which was followed by artificial aging at $83^{\circ} \mathrm{C}$. This approach was chosen based on successful resolutionizing done with sixty-day aged castings from the same foundry. In that study, both hardness and strength dropped after ten-second exposure to temperatures of were $850 \mathrm{~K}, 890 \mathrm{~K}, 940 \mathrm{~K}$, and $977 \mathrm{~K}$. Both hardness and strength lowered after resolution treatment, then recovered upon re-aging as indicated in table $3 \mathrm{a}$ and $3 \mathrm{~b}$. 
Table 3a: Strength Results of Solution Treatment.

$\begin{array}{lcccc} & \begin{array}{c}\text { Before } \\ \text { Treatment } \\ \text { Average } \\ \text { Strength } \\ \text { (psi) }\end{array} & \begin{array}{c}\text { After } \\ \text { Treatment } \\ \text { Average } \\ \text { Strength } \\ \text { (psi) }\end{array} & \begin{array}{c}\text { After Re- } \\ \text { aging } \\ \text { 30days } \\ \text { Average } \\ \text { Strength } \\ \text { (psi }\end{array} \\ \text { Temp. } & \text { Bar Set } & 37330 & 35387 & 377434 \\ 850 \mathrm{~K} & 3 & 38512 & 35743 & 38642 \\ 890 \mathrm{~K} & 4 & 38672 & 35960 & 39484 \\ 940 \mathrm{~K} & 5 & 38389 & 35474 & 37598 \\ 977 \mathrm{~K} & 6 & & & \end{array}$

Table 3b-Brinell Hardness Result After Solution Treatment

$\begin{array}{lcccr} & & \begin{array}{c}\text { Before } \\ \text { Treatment } \\ \text { Average } \\ \text { BHN }\end{array} & \begin{array}{c}\text { After } \\ \text { Treatment } \\ \text { Average } \\ \text { BHN }\end{array} & \begin{array}{c}\text { After Re- } \\ \text { aging } \\ \text { 30days } \\ \text { Average } \\ \text { BHN }\end{array} \\ \text { Temp. } & \text { Bar Set } & 203 & 201 & 213 \\ 850 \mathrm{~K} & 3 & 209 & 202 & 210 \\ 890 \mathrm{~K} & 4 & 210 & 207 & 204 \\ 940 \mathrm{~K} & 5 & 209 & 208 & 212 \\ 977 \mathrm{~K} & 6 & 209\end{array}$

The final accelerated aging test used resolutionizing to start the process followed by aging at $83^{\circ} \mathrm{C}$. The results almost show an Avrami distribution (figure 10a) of the aging data, with the exception of a small drop of the strength at $\mathrm{T}=60$ minutes. This drop may be the development of a new precipitate phase. Previous room temperature data from the same casting ladle at the same foundry demonstrate the same type of behavior, but on an extended time scale (refer to fig. 10b). Further work will concentrate on this phenomenon. This may indicate a two-step process. It should be noted that the resolutionizing technique did not work as well on this lot as it did on the initial temperature study, probably due to temperature distribution in the resolution furnace. One will note that the original starting strength as cast for this lot was $256 \mathrm{MPA}$, but it only dropped to $268 \mathrm{MPa}$ on resolutionizing. 


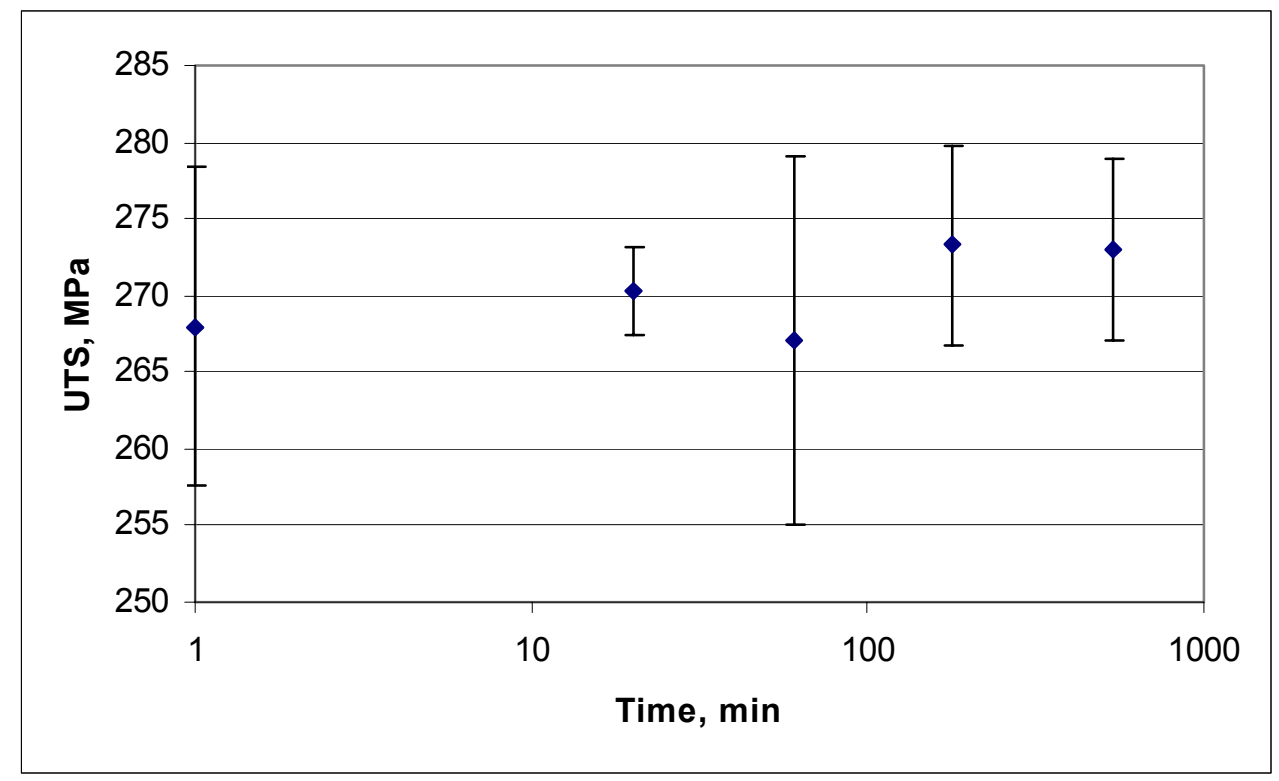

Figure 10a: Age Strengthening Data for the Resolutionized Gray Iron from Foundry $D, S$ artificially Aged at $83^{\circ} \mathrm{C}$.

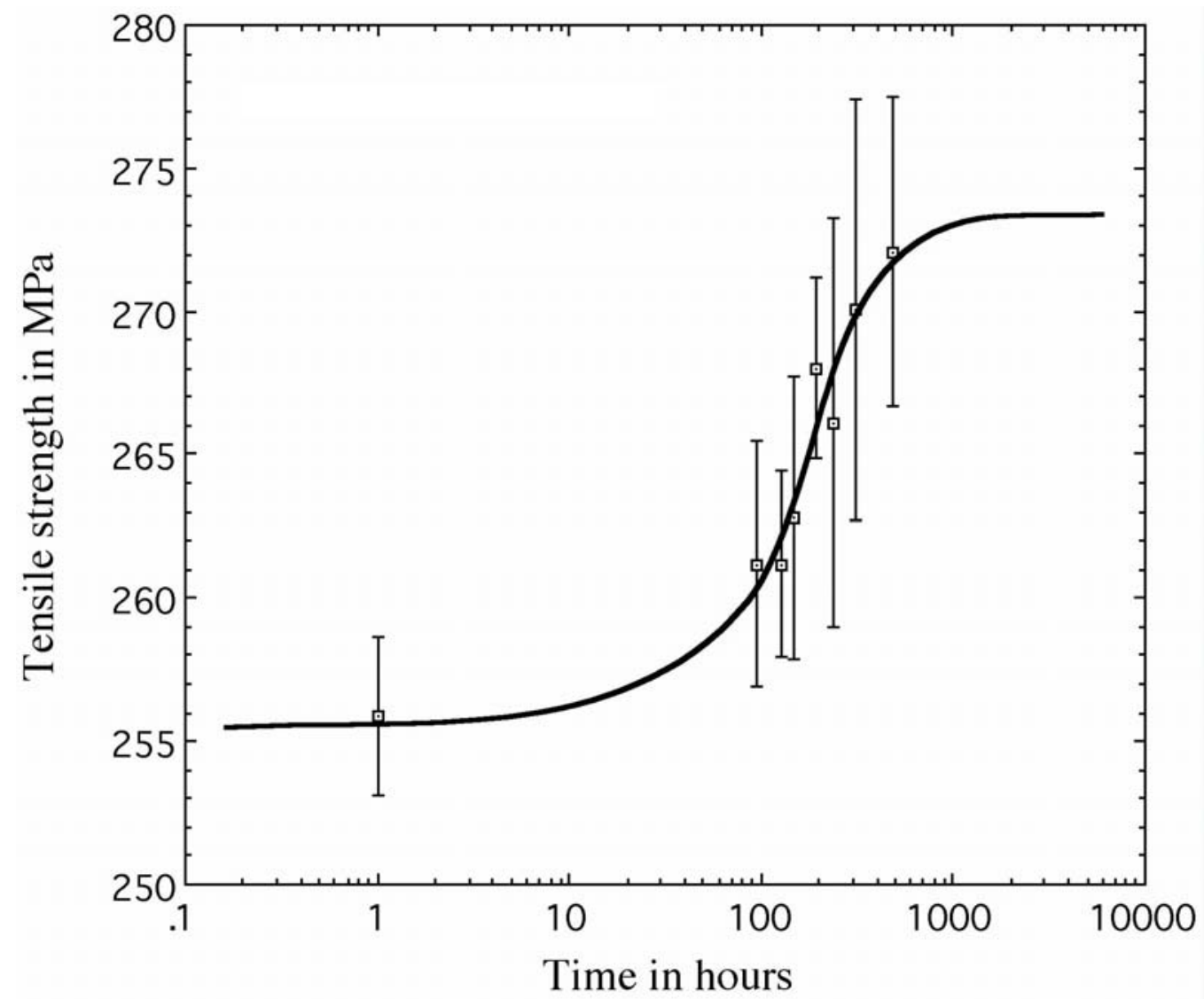

Figure 10b: Room Temperature Age Strengthening Data from the Same Ladle as in figure 10a. 


\section{Machinability}

Machinability tests were conducted with gray iron samples collected from three foundries (denoted by foundry C, D, and G). The parts included clutch discs and brake discs. Facing cuts were produced using a multi-operational machining tool.

Measurements included tool life, tilt (non-parallelism), surface finish, and power usage. Figure 11 shows that tool life improved dramatically with aging for the gray irons produced at foundries $\mathrm{C}$ and $\mathrm{D}$. The number of parts machined before tool failure follows a logarithmic curve with respect to the length of aging time prior to machining.

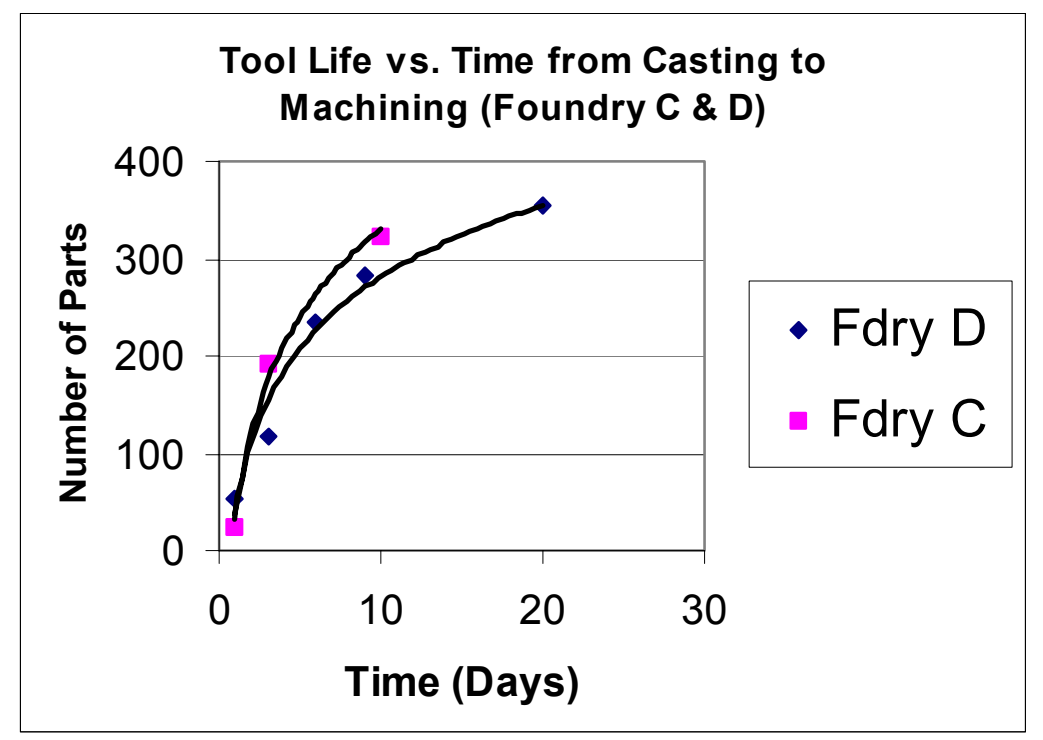

Figure 11: Effect of Aging on Tool Life for Foundry C and D Gray Iron.

As the tilt increased, the machine operator introduced an offset to compensate. The tilt data was adjusted for offsets during machining and plotted in figures 12 and 13 for the foundry $\mathrm{C}$ and $\mathrm{G}$ gray iron samples, respectively. The data for each day was fitted with a linear regression line and the slopes were plotted against aging time. The slopes and $\mathrm{R}^{2}$ values for each day can be seen in table 3 . Figure 14 and figure 15 show that the slope of the regression lines decreased with aging time. This indicates that the tilt rate decreased in the machined parts as they aged.

Table 3: Tilt Regression Data for Foundries C and G.

\begin{tabular}{|c|c|c|c|c|c|}
\hline \multicolumn{3}{|c|}{ Foundry C } & \multicolumn{3}{c|}{ Foundry G } \\
\hline Day & Slope & $\mathrm{R}^{2}$ & Day & Slope & $\mathrm{R}^{2}$ \\
\hline 1 & 0.0044 & 0.90 & 1 & 0.0151 & 0.82 \\
\hline 3 & 0.0012 & 0.76 & 10 & 0.0013 & 0.85 \\
\hline 10 & 0 & 0.18 & 30 & 0.0004 & 0.70 \\
\hline & & & & & \\
\hline
\end{tabular}




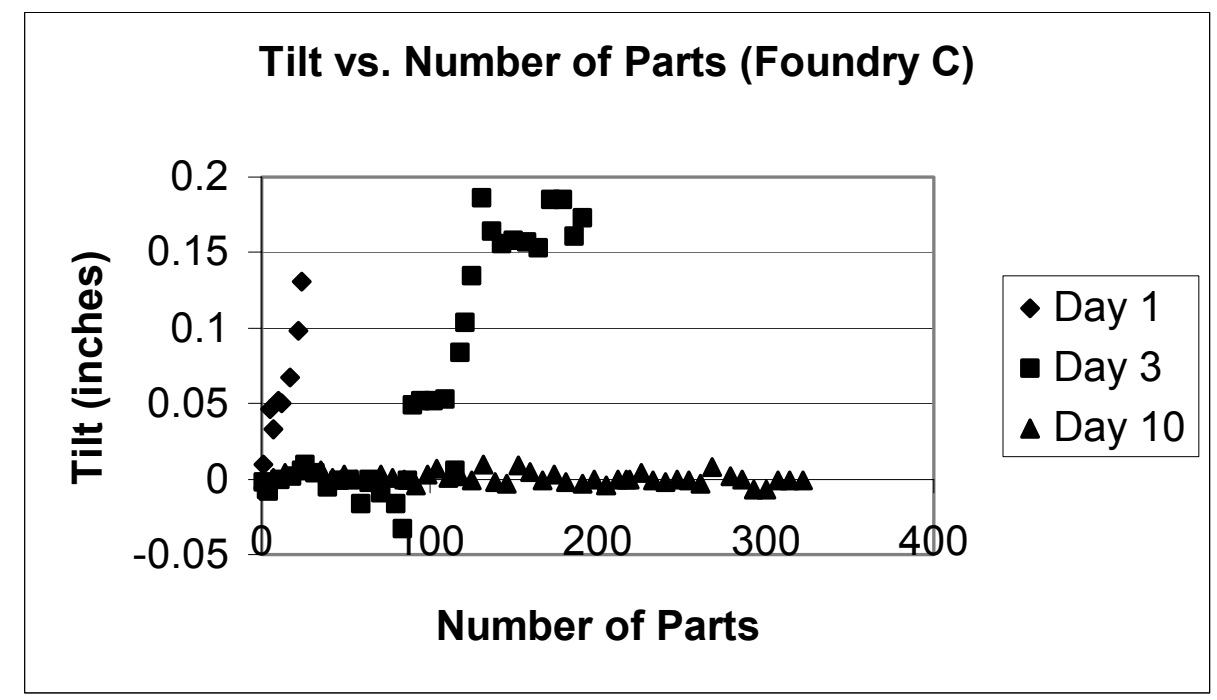

Figure 12: The "Tilt" (Non-Parallelism) Measured During Machining Runs at Different Aging Times for Foundry C Brake Discs.

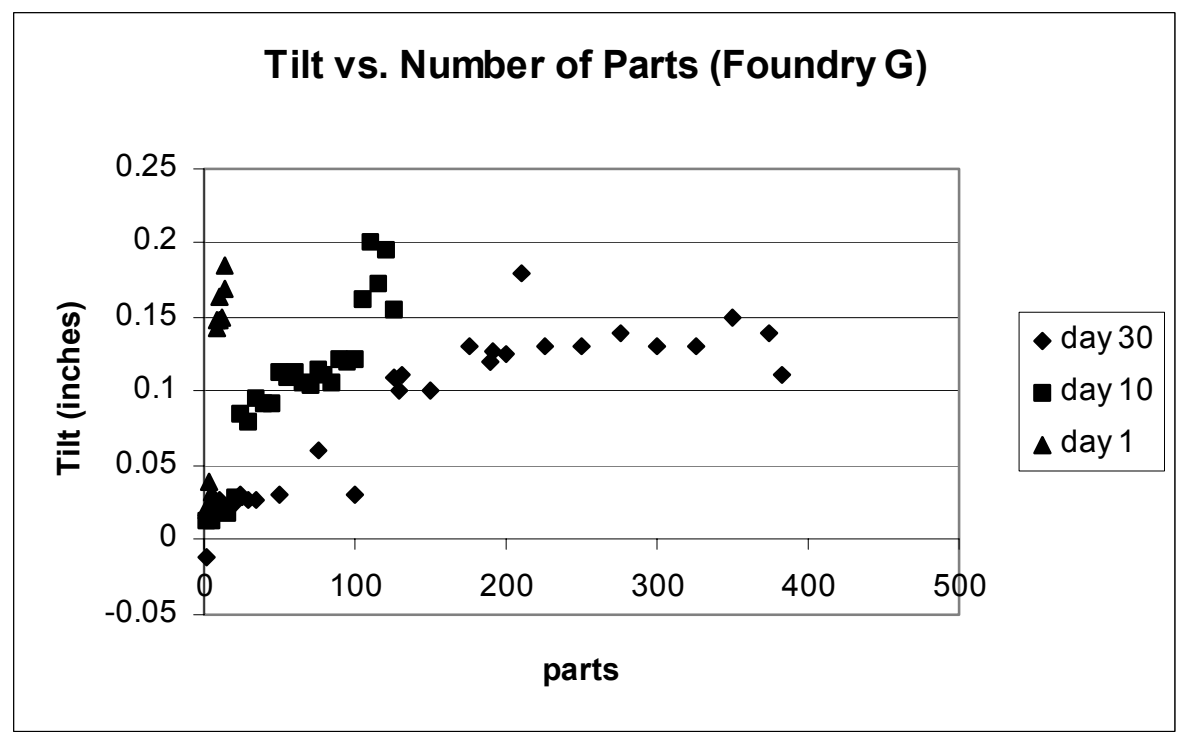

Figure 13: The Tilt measured During Machining Runs at Different Aging Times for Foundry G Brake Discs. 


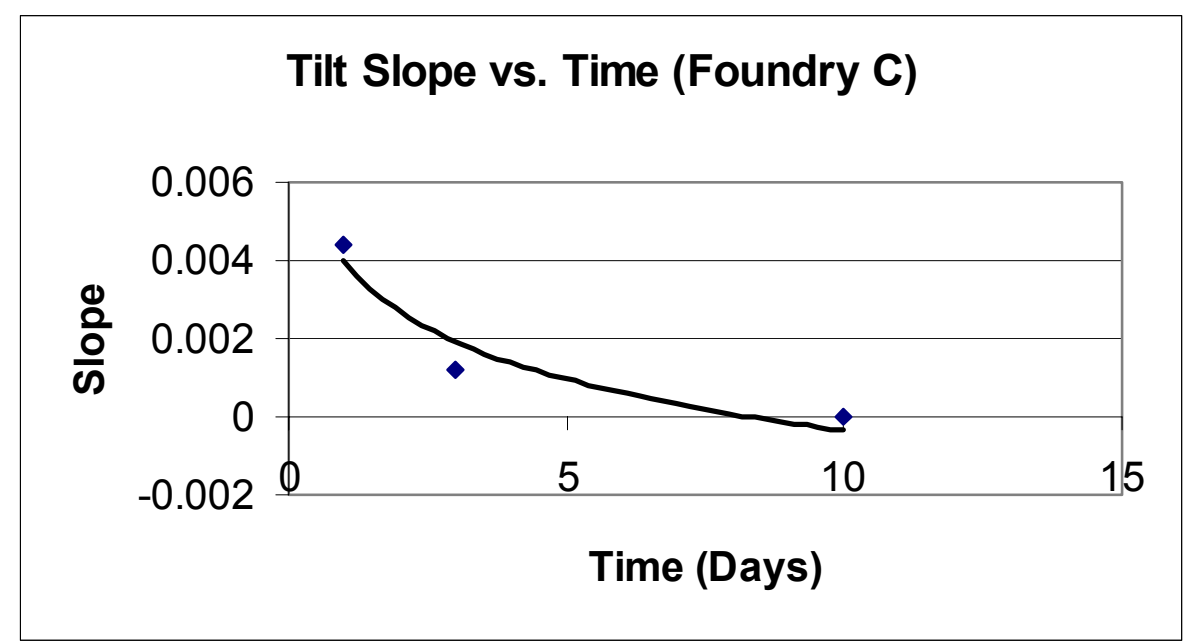

Figure 14: The Rate of Tilt Increase During Machining of Foundry C Brake Dises Decreases with Aging Time.

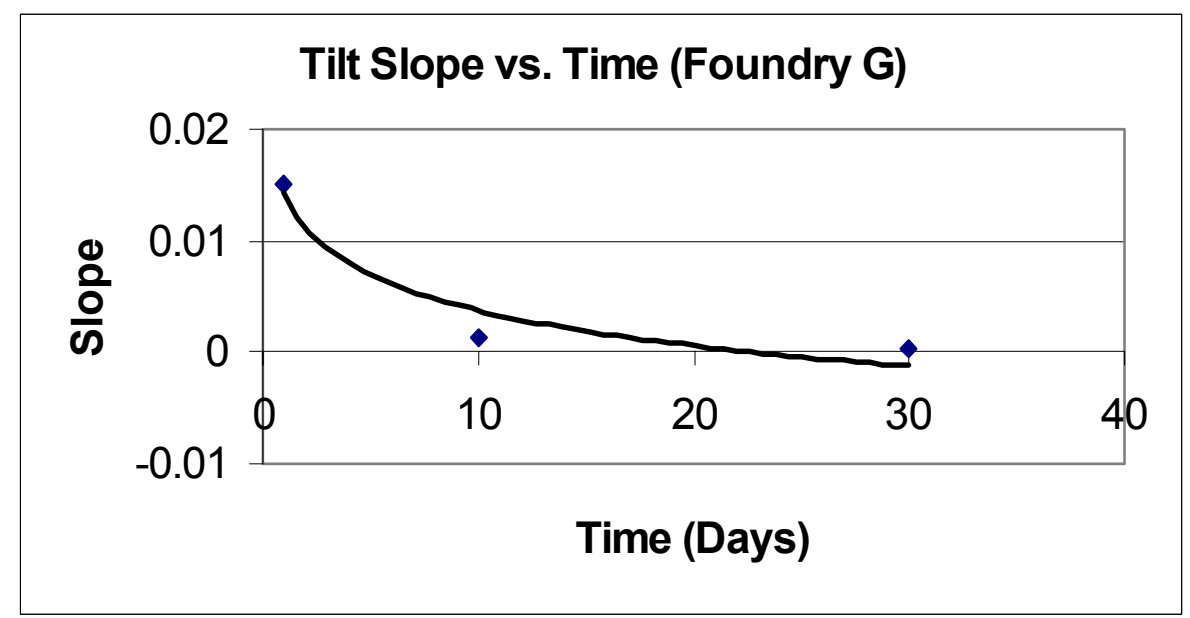

Figure 15: The Rate of Tilt Increase During Machining of Foundry G Brake Discs Decreases with Aging Time.

The surface finish of the machined parts was measured for the foundry C and D gray iron samples. Figures 16 and 17 show that the rate of surface finish deterioration on one tool decreased as the samples were aged for three days for both gray irons. The surface finish did not improve after day three, but leveled out to a relatively constant behavior over the number of parts machined on a given day. The rate of deterioration of surface finish was determined by performing linear regressions on the data for each day. The slopes and $R^{2}$ values for foundries $C$ and $D$ are shown in table 4 . Figure 18 shows that the surface finish deterioration rate appears to decrease with increasing aging time up to a aging time between three and ten days at room temperature. 
Table 4: Surface Finish Regression Data for Foundries C and D.

\begin{tabular}{|c|c|c|c|c|c|c|}
\hline & Foundry C & & & & Foundry D & \\
\hline Day & Slope & $\mathrm{R}^{2}$ & & Day & Slope & $\mathrm{R}^{2}$ \\
\hline 1 & 0.1375 & 0.94 & & 1 & 0.7223 & 0.63 \\
\hline 3 & 0.0039 & 0.42 & & 3 & -0.0411 & 0.006 \\
\hline 10 & 0.00003 & 0.0002 & & 6 & -0.0091 & 0.0042 \\
\hline & & & & 9 & 0.0756 & 0.396 \\
\hline & & & & 20 & 0.1264 & 0.693 \\
\hline
\end{tabular}

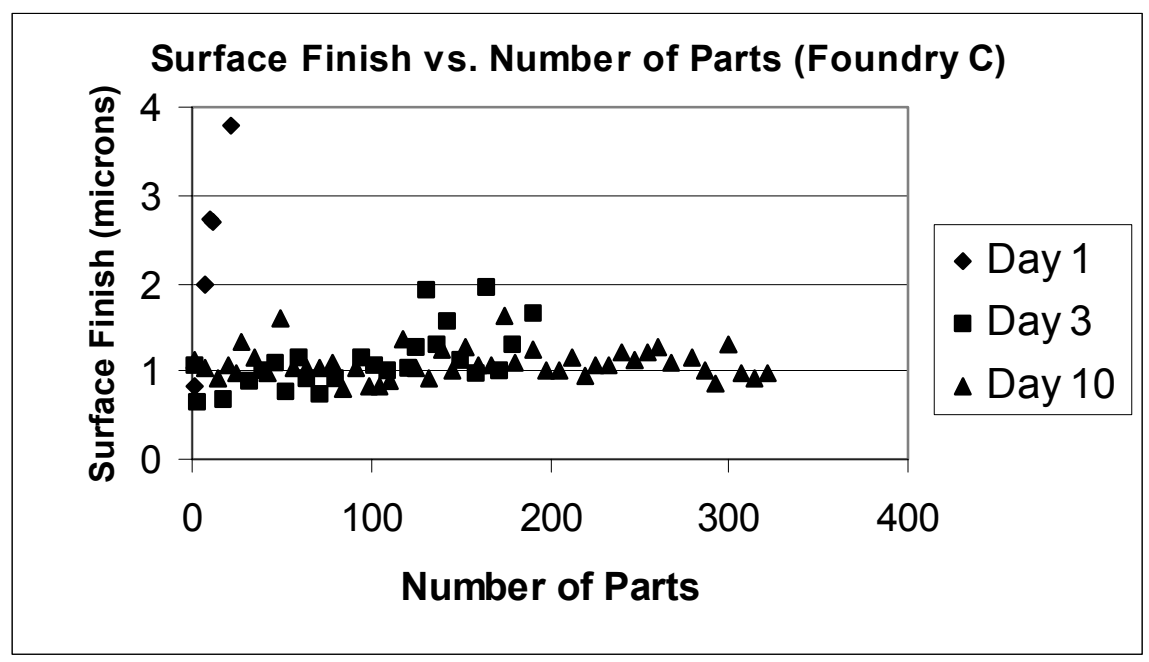

Figure 16: The Surface Finish Measured During Machining Runs at Different Aging Times for Foundry C Brake Discs.

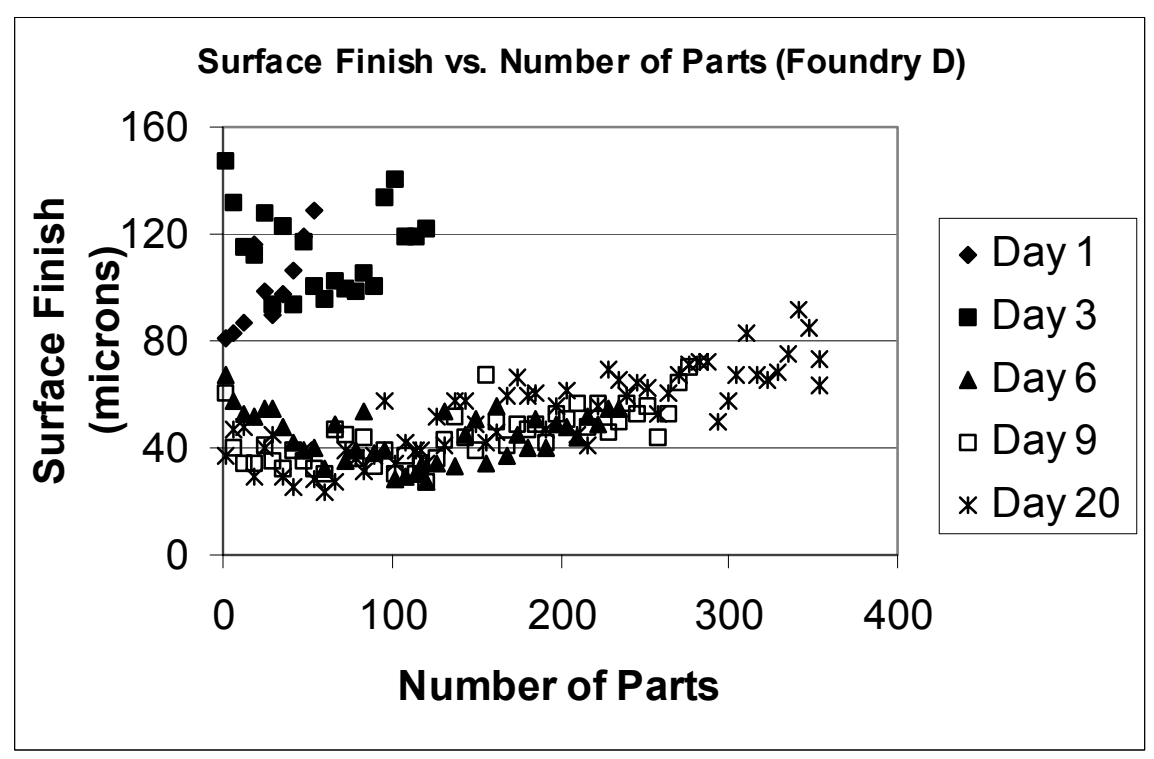

Figure 17: The Surface Finish Measured During Machining Runs at Different Aging Times for Foundry D Clutch Discs. 


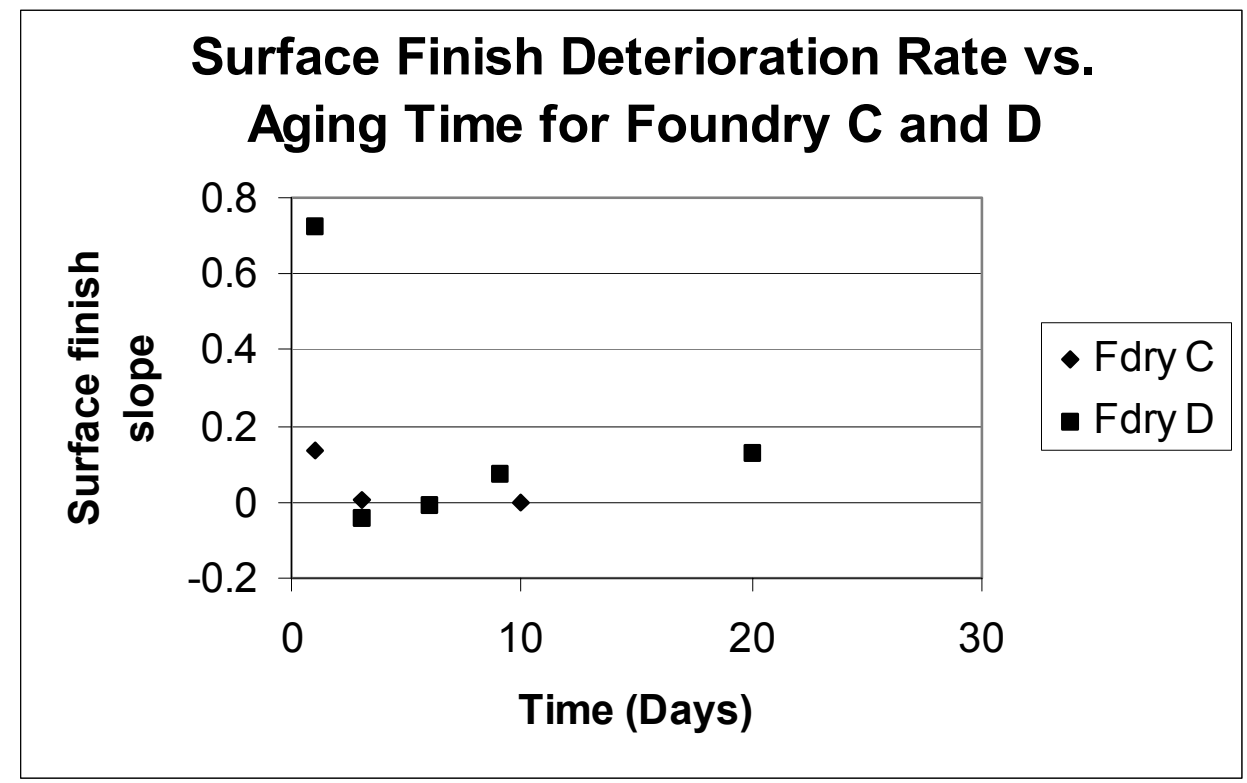

Figure 18: The Effect of Aging on the Rate of Surface Finish Deterioration during Machining for Foundries $C$ and $D$.

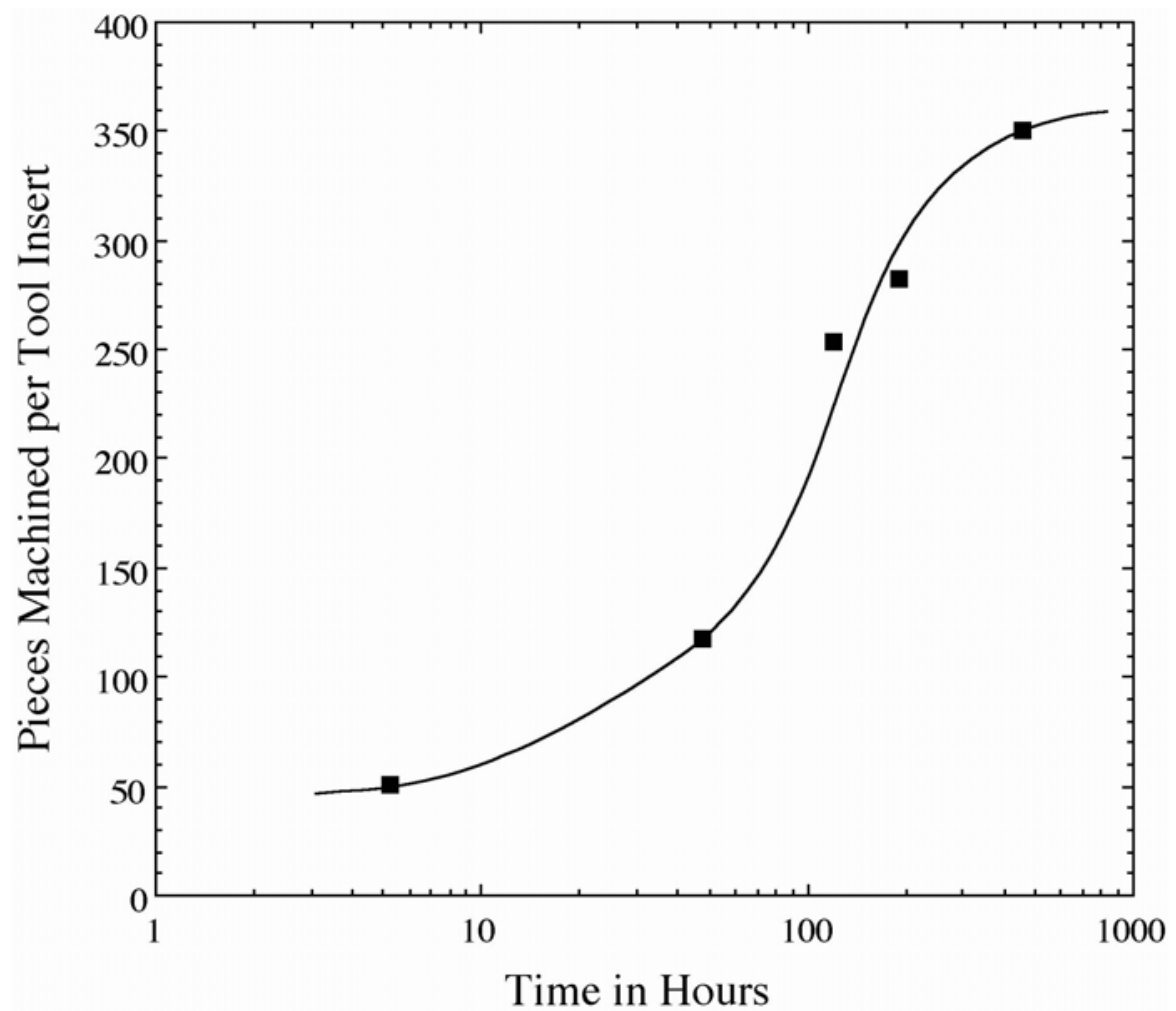

Figure 19: Machinability data for Foundry D. 
Another machinability study of Foundry D cast iron showed an increase in the number of parts produced per tool insert with increasing aging time. Note that the increase in machinability approximately coincides with the increase in tensile strength for foundry D. Both follow an Avrami distribution. Figure 19 is the machinability data for a machinability study with Foundry D castings. Figure 20 is the Avrami plot of strength versus time for the same run of castings at foundry $\mathrm{D}$ taken on days corresponding to the machinability tests.

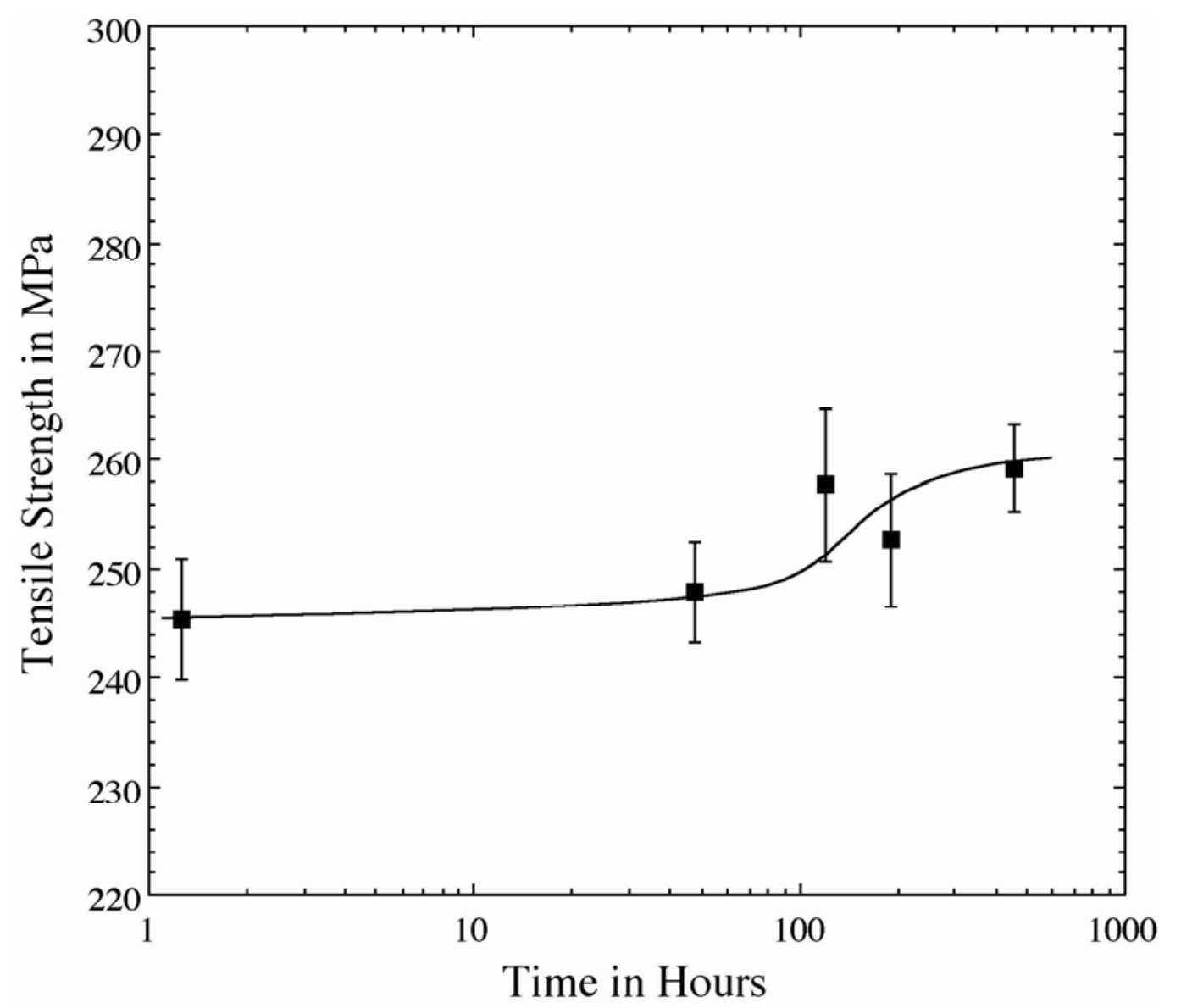

Figure 20: Avrami Plot of Strength of Foundry D Iron used for the Machinability Study Referenced in Figure 19.

\section{$\underline{\text { Ductile Iron }}$}

A preliminary study of ductile iron was included in this program. Four ductile irons were studied during this project. One of them was inconclusive due to sulfur contamination in the ladle. The quench and tempered iron did not demonstrate any age strengthening. It is suspected that the aging was all accomplished in the temper as accelerated aging based on the data from accelerated aging of gray iron. The two remaining irons did show age strengthening. They were both as-cast (not heat treated) 
from the same foundry, one of them being an 80-55-06 grade, and the other one a 65-4512 grade. However, the 65-45-12 (figure 21) exhibited a more obvious age strengthening pattern than the 80-55-06 (figure 22).

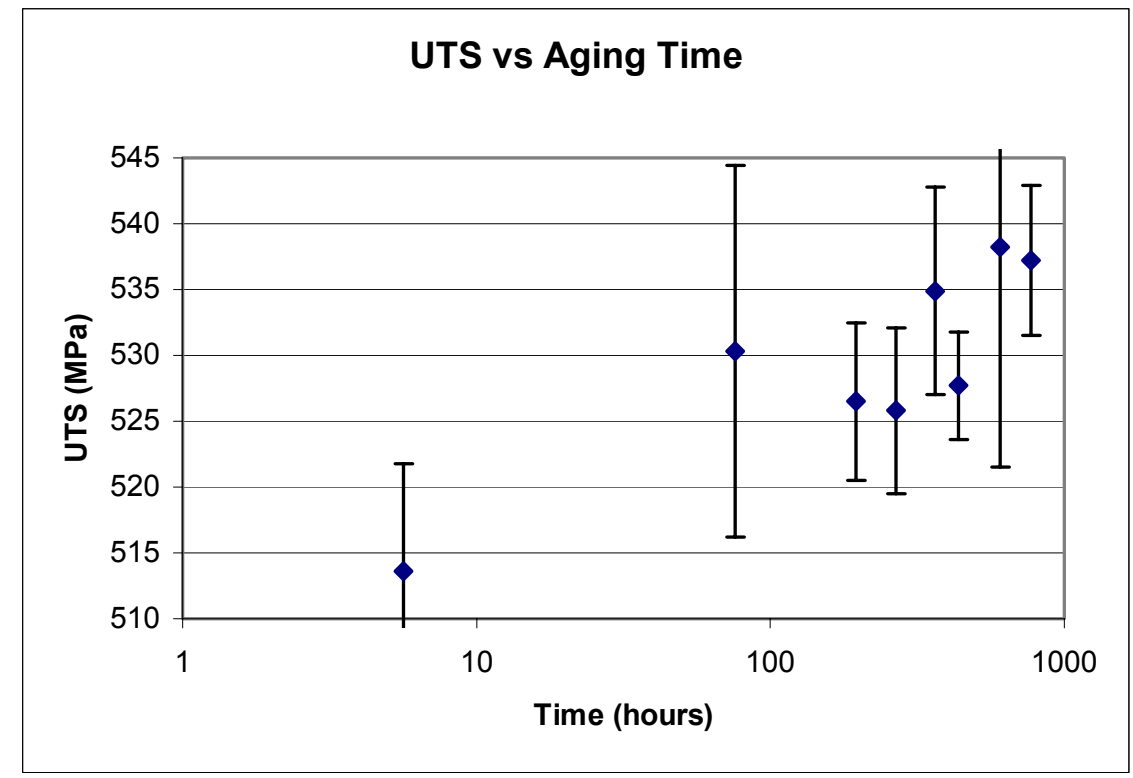

Figure 21: Age Strengthening Data for the 65-45-12 Ductile Iron.

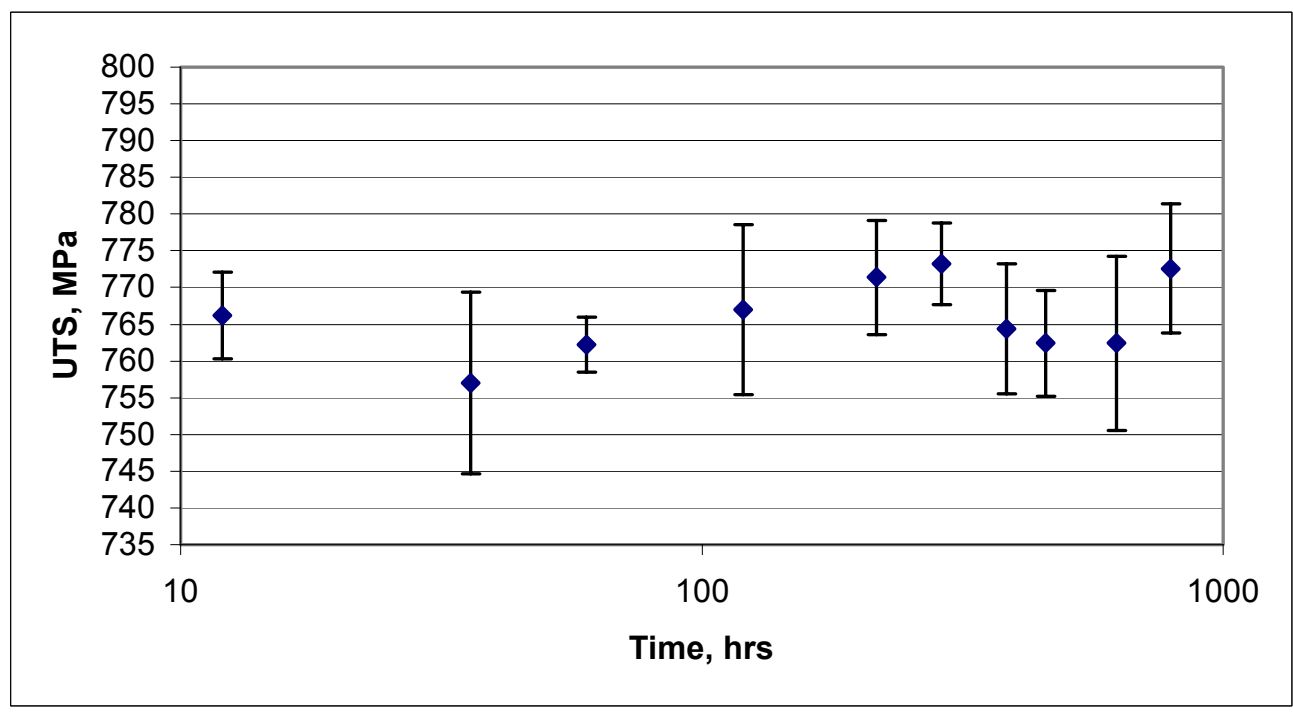

Figure 22: Age Strengthening Data for the 80-55-06 Ductile Iron.

An Avrami curve (sigmoidal pattern) could be fitted through the data for both irons. Both of the distributions show a slight drop followed by a steep increase $\left(3^{\text {rd }}\right.$ data point on fig. $21,7^{\text {th }}$ on figure 22 ). This is similar to the gray iron data (Figure $10 \mathrm{~b}$ for 
example). It is speculated that this "drop" might be the development of a new precipitate phase. This would be the analogue of the aluminum-copper alloy aging process

(Smallman, 1984) The 80-55-06 would need more data points to have a distribution close to the one in figure 21 . Also, the time to fully age the ductile iron may be longer than the class 30 gray iron for which we have most of the data, due to longer diffusion distances in the "free ferrite". In future work, the room temperature aging for ductile iron might be taken to 50 or 60 days.

\section{$\underline{\text { Microhardness }}$}

Microhardness measurements were made on the free ferrite regions of 65-45-12 grade. The variation of microhardness with aging time is shown in Figure 23. Simple averages do not give a good picture of the whole data range because there was a significant scatter in data. Error bars representing one standard deviation were used to account for that scatter. An increase in the microhardness was observed. The increase in microhardness ranged from 3\% to a high of 37\% compared to the data for day 1 (aged for $5.65 \mathrm{hrs}$ ). This would indicate that the maximum microhardness is obtained at aging time of 25 days. Microhardness for day 32 was not measured due to equipment failure. It can be noted that the increase in microhardness corresponds to the increase in strength with aging time (figure 21), and it was determined to be statistically significant. 


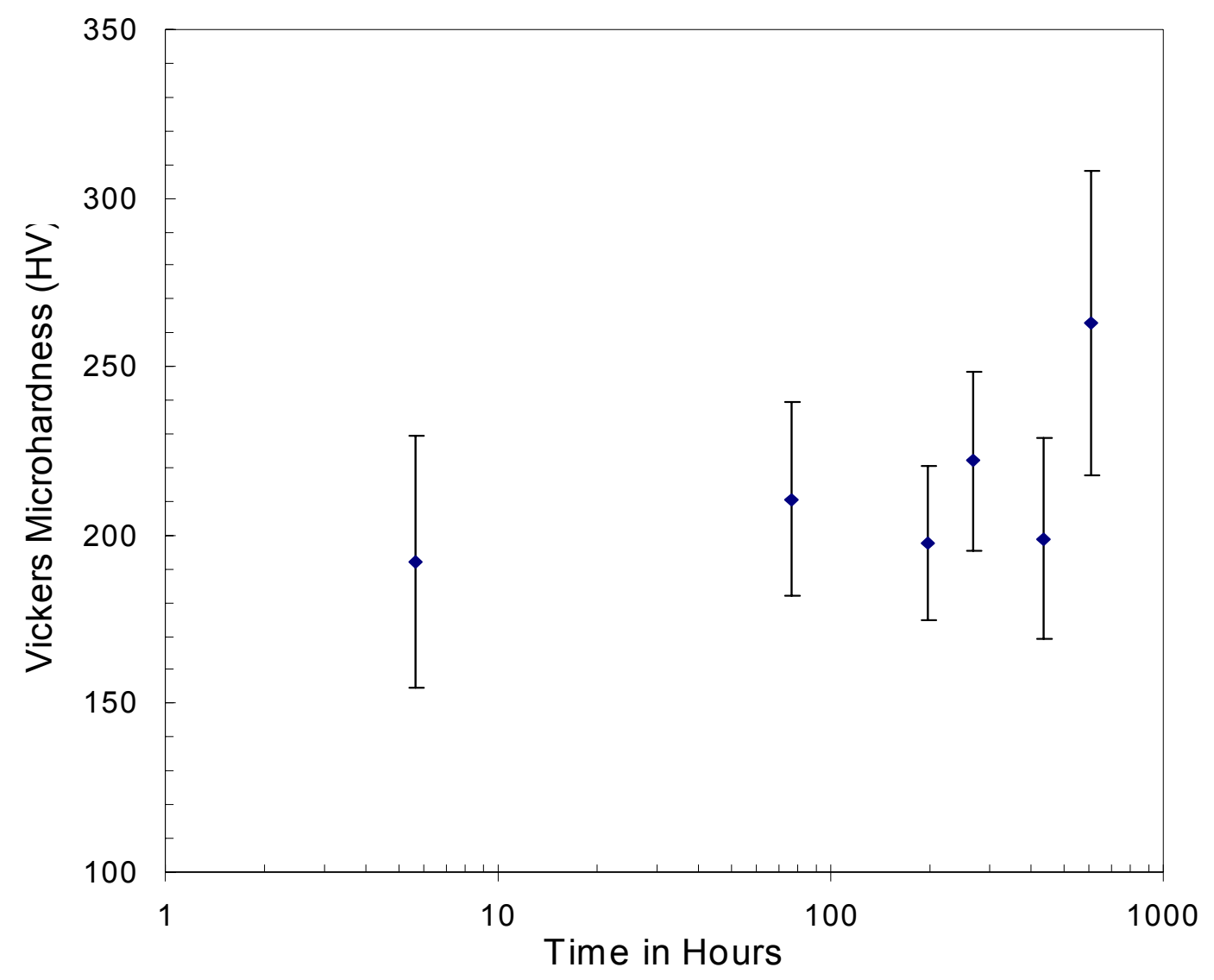

Figure 23: Microhardness Data for the 65-45-12 Ductile Iron. An Increase in the Hardness with Aging Time can be Observed.

\section{$\underline{\text { IV. Discussion of Results }}$}

\section{$\underline{\text { Strength and Hardness }}$}

In the earlier work (Nicola and Richards, 1999) a change in hardness was not detectable in room temperature aging and a logarithmic model was used to fit the strength data. In subsequent research reported here, it was found that the data on strength versus time approximately fit an Avrami-Johnson-Mehl curve with the exception of a drop and recovery at about sixty to eighty percent completion. As mentioned earlier, this drop and recovery may be due to a change in dominant precipitate species. Also, careful sample preparation revealed that Brinell hardness was increasing during aging with the same functional time pattern. This kind of pattern is noted in the age strengthening of alloys that form Guinier Preston zones, and then change to another type of precipitate structure as aging progresses. An interesting observation was that the secant modulus of the gray iron tended to increase with the age strengthening. This would be consistent with the 
type of dislocation locking mechanism that could occur with a Fe-N or Fe-C-N precipitate.

$\underline{\text { Nitrogen Analysis }}$

The neutron scattering study of sample 14A, a nitrogen-rich gray iron, aged 28 days, revealed a particle with a diameter of 2-4 $\mathrm{nm}$ or an ordered array of particles with an interparticle distance of $3.7 \mathrm{~nm}$. The size of this structure is significant in that it is on the same order of magnitude as Guinier-Preston (GP) zones. Nitrogen GP zones have been shown to form in Fe-N alloys at low temperatures (Wada, 1989). The presence of this particle also coincides with the age strengthening of the gray iron. The gray iron in sample $14 \mathrm{~A}$ increased in strength $5.4 \%$ between day one and day 28 . The gray iron in sample 7A (standard gray iron) also increased in strength (7.4\%) between day one and day 28. The scatter in the sample 7A data due to sample thickness prevents sufficient peak resolution to detect any nanometer-scale particles. The precipitation of iron nitrides could possibly be the mechanism by which age strengthening occurs. However, there is insufficient data at this time to draw a conclusion about strengthening mechanisms from neutron scattering alone. The gray irons used in this study are very strong "scatterers" of neutrons due to large numbers of micron-scale inhomogeneities. It is possible that the peak resolution is due to the thin specimen size. The particle may have been present on day one but the thicker specimens caused the peak to be unresolved due to diffuse scattering.

The amount of free nitrogen correlates with the rate of strengthening in the gray irons from foundries $\mathrm{C}$ and $\mathrm{D}$ as illustrated in figure 3 . The dependence of strengthening rate on free nitrogen suggests that nitrides of iron or a mobile electropositive species may be forming over time, resulting in a strength increase. Although boron may have enough mobility and has been considered, the logical choice seems to be iron nitride precipitation because iron nitrides have been shown to form in iron-nitrogen alloys at low temperatures (Wada, 1989). Kinetic studies have shown accelerated aging to near full strength at $182^{\circ} \mathrm{C}\left(360^{\circ} \mathrm{F}\right)$ and accelerated aging to lower strength levels at $85^{\circ} \mathrm{C}\left(185^{\circ} \mathrm{F}\right)$ in ten hours. The time scale over which the accelerated aging occurred at $182^{\circ} \mathrm{C}\left(360^{\circ} \mathrm{F}\right)$ matches very well with the observed time scale for precipitation in the iron-nitrogen system at $250^{\circ} \mathrm{C}\left(480^{\circ} \mathrm{F}\right)$ by Wert (Wert, 1954).

The DSC work shows an exothermic peak at $200-250^{\circ} \mathrm{C}$ in gray iron that aged strengthened. This could be either $\alpha$ ' $\mathrm{Fe}_{16} \mathrm{~N}_{2}$ transforming to stable $\mathrm{Fe}_{4} \mathrm{~N}(\gamma$ ') or the decomposition of carbonitride to form $\mathrm{Fe}_{3} \mathrm{C}$ and $\gamma^{\prime}$. The DSC measurements also show a reaction that could be the ternary eutectoid in the $\mathrm{Fe}-\mathrm{C}-\mathrm{N}$ system.

\section{$\underline{\text { Artificial Aging }}$}

The first artificial aging study used freezer storage at $-13^{\circ} \mathrm{C}\left(4^{\circ} \mathrm{F}\right)$ to inhibit aging during machining and prior to elevated temperature treatment. Subsequently, it was found that over a sixty-day time, the freezer storage did inhibit aging but only partially. 
The first aging study is shown in figure 7 , where the strength increased more rapidly with an aging temperature of $149^{\circ} \mathrm{C}\left(360^{\circ} \mathrm{F}\right)$ versus $70^{\circ} \mathrm{C}\left(185^{\circ} \mathrm{F}\right)$. Since the artificial aging samples were kept in a freezer and the room temperature samples were not, There is uncertainty in the "real" start time of aging in this study. The strength of this heat of iron was $308 \mathrm{MPa}$ (44600 psi) after room temperature aging for sixty days. It is apparent that maximum strength was not achieved by this attempt at artificial aging.

In the second artificial aging study, dry ice was used to keep the samples cold. They were water quenched after shakeout and stored in dry ice until and between machining operations. This kinetic study used additional 10 -hour tests at $149^{\circ} \mathrm{C}\left(360^{\circ} \mathrm{F}\right)$ and additional higher temperature tests at $233^{\circ} \mathrm{C}\left(545^{\circ} \mathrm{F}\right)$. Figure 8 indicates that the strengths are near the maximum strength after aging ten hours at $149^{\circ} \mathrm{C}\left(360^{\circ} \mathrm{F}\right)$ and that at $233^{\circ} \mathrm{C}\left(545^{\circ} \mathrm{F}\right)$ they are either near the maximum at three hours or that the maximum strength occurred between one and three hours. Note that the maximum strength at sixty days was lower than the sixty-day strength for the iron used in the first artificial aging study, due to a higher carbon equivalent iron. This was due to the participating foundry taking advantage of age strengthening to raise the carbon equivalent of their gray iron and reap the energy savings due to improved yield.

Resolution tests of ten seconds at temperatures at which the solubility of nitrogen in ferrite is substantially increased demonstrated loss of strength that was recovered on subsequent room temperature aging.

One accelerated aging test was done with resolutionized bars using and $83^{\circ} \mathrm{C}$ aging temperature. The iron was a large batch of production iron bars on which we had room temperature aging data. Although full resolution did not occur, the strength recovery followed an Avrami type curve with the late stage drop of strength followed by increasing strength. The form of the kinetic curve was similar to the room temperature data for the same lot of test bars. A preliminary estimate of activation energy by comparing the two curves is $80 \mathrm{~kJ} /$ mole. This is similar to the activation energies for nitrogen and carbon diffusion.

\section{Machinability}

The machinability studies conducted on foundry C, D, and G samples indicate that the machinability of the gray irons improves with aging time. As figures 10 and 11 indicate, tool life is dramatically improved with aging time for foundry $\mathrm{C}$ and $\mathrm{D}$ gray irons. The number of castings machined prior to tool failure shows an Avrami relationship with aging time. Tilt rate and surface finish deterioration rate decrease with aging. The improvement in machinability coincides with the age strengthening behavior of the gray iron samples. As the strength increases, the machinability improves. In the early work, no hardness increase was detected, so the machinability was thought to be related to the hardness-to-tensile ratio. Later work proved that bulk hardness was 
increasing and could be detected by careful sample preparation to avoid heating the sample during preparation.

The data for this study was collected from a multi-operational machine in a production environment. This is time-consuming and quite expensive so that it is difficult to get enough data to have statistically significant data. Many problems occur during production studies. For instance, the machine will jam if a part is loaded incorrectly. In some cases, one tool failed before the conclusion of the test. As a result, all of the other processes occurring at this time were affected. This explains the scatter in the above plots and the poor $\mathrm{R}^{2}$ values obtained from linear regressions. Another problem with production run machinability tests is that different locations have different criteria for tool failure and performance. The result of this is that the machinability study is not very "clean" statistically. However, conducting in-plant studies was valuable to the investigators for developing an understanding of the engineering problem of machining. This will be helpful in doing laboratory measurements of machinability for design ofappropriate tests.

The improved machinability resulting from aging has yet to be fully rationalized. However, it should be remembered that gray irons are fundamentally a composite material that behaves in a $n$ elastic-brittle manner. Thus, chip formation models of plastic shear to fracture are not directly relevant. In this regard, the higher secant modulus in aged gray iron may be important. If chip breakage were related to the elastic deflection of the chip, then the aged iron would exhibit higher stress and the probability of finding a critical flaw would be greater. Consequently machining chips on average would be smaller and that would reduce the amount of tool friction and tool wear. Another feature to consider is built-up edge stability on the tool.

Alternatively, one may want to consider the machinability results of Marwanga (Marwanga, 1997) where it was shown that the degree of scalloping at the surface and depth of damage layer beneath the tool decreases as the strength class of the iron increases. While this may be in part due to graphite flake size, it may also be related to matrix strength. In any event, the cyclic loading range for the tool and the work of deformation accompanying the cut decreases with the stronger irons.

In the future, some of the machinability studies should be conducted on a single operation machine with fewer systematic variables that occur in multi-operation production facilities. This would be in conjunction with a tool dynamometer and high speed data acquisition. Thus machinability data will be obtained that will reveal a more detailed understanding of the mechanism by which aging affects the machinability.

\section{$\underline{\text { Microhardness }}$}

Age strengthening had an effect on the microhardness free ferrite in ductile iron. A test of significance (Student's t -test) shows 100\% confidence that results from day one versus day 25 are from different populations. This indicates that the results from Day 1 
and Day 25 are distinctly different and is an indication of increase in microhardness due to aging. The increase in microhardness ranged from $3 \%$ to a high of $37 \%$. Tensile tests were conducted on bars drawn from ductile iron specimens aged for different periods of time prior to measuring microhardness. The variation of tensile strength with aging time followed the same pattern as the variation of Vickers microhardness with aging time. This can be seen in Figures 21 and 23.

\section{$\underline{\text { General Discussion }}$}

There is much evidence to support a nitride or carbo-nitride precipitate or preprecipitate cluster as the mechanism to enhance strength of the cast irons by dislocation locking in the ferrite (either free ferrite or ferrite in the pearlite plates). The kinetics of strength and hardness increase follow an Avrami or Johnson-Mehl sigmoidal curve except for one step that appears at about sixty to eighty percent complete. This step may mean that two different precipitates occur and that there is a transition from one to the other during aging. This would not be unreasonable considering the differential scanning calorimetry results. The fact that the rate is significant at room temperature argues for an interstitial species in ferrite such as carbon or nitrogen that would have significant diffusional mobility at room temperature. The approximate activation energy for the reaction also suggests carbon or nitrogen. Neutron scattering suggests a precipitate of 2-4 $\mathrm{nm}$ in size. The DSC exothermic peak at $250^{\circ} \mathrm{C}$ corresponds to the reported transformation of $\mathrm{Fe}_{16} \mathrm{~N}_{2}\left(\alpha^{\prime \prime}\right)$ to $\mathrm{Fe}_{4} \mathrm{~N}\left(\gamma^{\prime}\right)$ (Enrietto, 1965). The amount of strengthening and rate seems to be affected by the amount of nitrogen in excess of the strongly nitride-forming alloying elements. Microhardness measurements of the free ferrite in 65-45-12 as cast ductile iron also showed age hardening to a statistically significant extent over a 25 -day period at room temperature. This indicates a structural change rather than residual stress.

More specific work is needed such as hot stage transmission electron microscopy to demonstrate the development of the effective nano-structure that these results suggest.

\section{$\underline{\text { V. Conclusions and Recommendations }}$}

The conclusions from this research are:

1.Statistically significant age strengthening of gray and ductile iron does occur and was demonstrated in twenty-eight of thirty-two gray iron compositions tested from eleven different foundries.

2. Brinell hardness also increases with age strengthening.

3. Machinability by industrial criteria improves with age strengthening, on roughly the same kinetic curve. 
4. Holding for short times (one to ten hours) at modestly elevated temperatures $\left(83^{\circ} \mathrm{C}\right.$ to $250^{\circ} \mathrm{C}$ ) accelerates the age strengthening process.

5. The activation energy for the accelerated process roughly corresponds to $84 \mathrm{KJ} / \mathrm{mole}$

6. A nano-precipitate or pre-precipitate cluster of a phase from the Fe-N or Fe-C-N system is a likely active species in the process.

7. Age-strengthening increases with nitrogen in solid solution on the ferrite.

8. The Avrami plots almost always show a step at about half to three fourths of full strength. This suggests a two-stage mechanism, which needs further investigation.

9. Microhardness of the free ferrite in as-cast 65-45-12 also showed the age-hardening.

The following are deployment recommendations:

1. Those foundries being required to inventory iron for machinability improvement should review the kinetics of aging of their iron. Most of the effect occurs in five to ten days at room temperature.

2. If feasible, it may be useful to take advantage of the mechanical properties of the aged alloys and increase the carbon equivalent of cast irons for a given specification in order to increase mold yield and save melting energy. Some participating sponsors have already done that.

3. Nitrogen content should be monitored periodically for cast irons that exhibit aging.

The following are recommendations for further research:

1. Hot stage transmission electron microscopy study of the ferrite phase in cast irons to identify precipitation reaction that may be responsible for age strengthening.

2. Better measurement of the activation energy of accelerated aging to assist with specifying the mechanism and design of manufacturing processes.

3. A tool dynamometer study with high-speed data acquisition to provide understanding of how age strengthening affects machinability.

4. Characterization of production machinability effects in age strengthening of ductile iron.

5. Determination of whether age strengthening exists in compacted graphite iron.

6. Additional studies of composition factors and longer time scale aging in ductile iron. 


\section{List of Papers Produced During This Contract}

1. W. M. Nicola and V. L. Richards, "Age Strengthening of Gray Cast Iron Phase II: Nitrogen and Melting Method Effects, " AFS Transactions, paper 00-127, (2000) page 233-238.

2. W. Nicola and V. L. Richards, "Age Strengthening of Gray Cast Iron Phase III: Effect of Aging Temperature," AFS Transactions, paper 01-081 (2001), pages 1085-1094.

3. J. Edington, V. L. Richards, and W. Nicola, "Age Strengthening of Gray Cast Iron: Nitrogen effects and Machinability," AFS Transactions, paper 02-120 (2002), p 983994.

4. Von L. Richards, D.C. Van Aken and Wayne Nicola "Age Strengthening of Gray Cast Iron", Seventh International Symposium on the Science and Processing of Cast Iron, 2002, paper number 76.

5. Von L. Richards, David C. Van Aken, and Wayne Nicola, "Age Strengthening of Gray Cast Iron: Kinetics, Mechanical Property Effects, “ AFS Transactions, paper 03037, (2003).

\section{Acknowledgements}

The investigators gratefully acknowledge the support US DOE under the contract number DE-FC07-00ID13851. The participating foundries made a significant in-kind contribution of technical manpower and production facilities. The project review and guidance from AFS 5H (gray iron research) and 5I (ductile iron research) committees was extremely valuable. Students from Tri-State University and University of MissouriRolla made a significant contribution.

\section{References}

Enrietto, J.F., Wells, M.G.H., and Morgan, E.R., "Quench Aging in Fe-Mn-C alloys," in Precipitation from Iron Base Alloys, edited by Gilbert R. Speich and John B. Clark, PP 141-171 Gordon and Breach, New York, (1963).

Izidbih, Mohamed Y. and Richards, Von L; "Age Strengthening Effect on Ductile Iron Microhardness" (unpublished)

Malinov, S.; Bottger, A.J.;Mittemeijer, E.J.; Pekelharing, M. I.; Somers, M.A.J.; "Phase Transformations and Phase Equilibria in the Fe-N System at Temperatures Below 573K,' Metallurgical and Materials Transactions A, (2001) 32A(1), pages 59-73. 
Marwenga, R. O., Quality Improvement through Microstructure Control for Superior Machinability of Cast Irons, Ph.D. Thesis, Pennsylvania State University, (R. Voigt, Advisor), p 111-148, (1997).

Nicola, W. M.; and Richards, V.; "Age Strengthening of Gray Cast Iron, Phase I: Statistical Verification,” AFS Transactions, p. 749 (1999).

Nicola, Wayne M.; and Richards, Von; "Age Strengthening of Gray Cast iron Phase III-Effect of Aging Temperature," AFS Transactions (paper 01-181), (2001).

Richards, V. L., Van Aken, D. C., Nicola, W., "Age Strengthening of Gray Cast Iron: Kinetics, Mechanical Property Effects”, AFS Transactions (paper 03-037), (2003).

Smallman, R.E., Modern Physical Metallurgy, Fourth Edition, Butterworth Heinemann, London, 1984, pages 381-3.

Thiyagarajan, P., IPNS Report, Argonne National Laboratory, 4-24-01.

Wada, M.; Fujii, A. ; Komazaki, T. ; and Mori, T.; "FIM Observation of Nitrogen GP Zones in Iron," Acta Metallurgica. v 37 n 9 Sep 1989 p 2349-2355

Wert, C., "Precipitation out of Dual Solid Solutions of Carbon and Nitrogen in AlphaIron", Acta Metallurgica, Vol. 2, p361, 1954. 